\title{
Review of the current technologies and performances of hydrogen compression for stationary and automotive applications
}

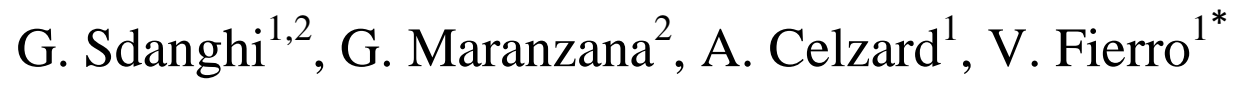

1 Institut Jean Lamour, UMR CNRS-Université de Lorraine $\mathrm{n}^{\circ} 7198$, ENSTIB, 27 rue Philippe Seguin, BP 21042 - 88051 EPINAL Cedex 9, France

2 Laboratoire d'Energétique et de Mécanique Théorique et Appliquée, UMR CNRSUniversité de Lorraine $\mathrm{n}^{\circ}$ 7563, 2 avenue de la Forêt de Haye, BP 160, F-54504 Vandœuvre-lès-Nancy, France

* Corresponding author. Tel: + 333292961 77. Fax: + 333292961 38. E-mail address : Vanessa.Fierro@univ-lorraine.fr (V. Fierro) 


\section{Abstract}

Hydrogen could play an important role as energy vector in the next decades in the frame of the Sustainable Development. It is the most abundant element of the universe, and virtually available everywhere, thus being a never-ending source of energy. Hydrogen can be directly converted into electric energy by using fuel cells, without producing toxic gases. Moreover, it can be produced by renewable sources such as biomass, solar and wind energies, thus having no impact on the environment. However, even if hydrogen offers a promising eco-friendly solution for the energy transition, in order to foreseen its wide use in both stationary and automotive applications, several issues related to its storage and delivery have to be solved. Indeed, hydrogen has lowest volumetric energy density among the commonly used fuels, i.e., $0.01079 \mathrm{MJ} / \mathrm{L}$ at atmospheric pressure. Compression is the direct solution to overcome this barrier. High pressures can indeed give satisfying energy densities. The present review summarises the state of the art of the most classical hydrogen compression technologies. The technical and design features of mechanical compressors, i.e., reciprocating, diaphragm, linear and ionic liquid compressors, as well as of innovative non-mechanical technologies specifically conceived for hydrogen applications, such as cryogenic, metal hydride, electrochemical and adsorption compressors, are presented. The basic operating principles and the performances potentially achievable for each compression technology are analysed. Specifically, their current uses in hydrogen applications, as well as their technological limits, are described outlining the possible actions to be taken for improving their performances.

Keywords: Hydrogen compression; Mechanical compressors; Cryogenic compressors; Metal hydride compressors; Electrochemical compressors; Adsorption compressors. 


\section{Introduction}

The growing global energy demand, as well as the increasing concerns about environmental pollution, has made hydrogen a realistic alternative to the traditional fossil fuels. The world energy consumption is indeed expected to double over the next half century, so significant changes in producing, distributing, storing and using energy are necessary (1). Hydrogen can be the ideal solution to all these issues. Hydrogen is the most abundant element in the universe, thus being a never-ending and renewable source of energy. Furthermore, hydrogen can be produced from renewable and sustainable resources, thus offering a promising eco-friendly solution for the energy transition expected in the next decades. Hydrogen production from water by electrolysis is nowadays considered the main sustainable alternative to hydrogen synthesis from fossil fuels (2). Hydrogen production from biomass has shown to be a cost effective solution as well, both by using supercritical water gasification (3) and fermentative processes (4). Solar energy is also another sustainable and environmentally friendly way to produce hydrogen $(5,6)$. Hydrogen exhibits the largest gravimetric energy density among non-nuclear fuels, and can be easily converted into thermal, mechanical and electrical energy (7). Its use in both stationary and automotive applications, such as fuel cells, offers a promising way to use electrical and thermal energies without impact on the environment, opening a new scenario in the use of sustainable energy all over the world (710).

Despite such advantages, two main issues prevent the generalised use of hydrogen as an efficient fuel, and with this, the energy transition towards a compelling fossil-free solution. Firstly, hydrogen is an energy vector, and this means that it is necessary to produce it before use, so energy is needed to synthesise hydrogen (11). Secondly, hydrogen exhibits the lowest volumetric energy density among the commonly used fuels, $0.01079 \mathrm{MJ} / \mathrm{L}$ at standard temperature and pressure (12), much lower than that of gasoline, $34 \mathrm{MJ} / \mathrm{L}$ (13). In order to 
increase this value, several methods have been developed: (i) compression in gas cylinders; (ii) liquefaction in cryogenic tanks; (iii) storage in metal hydride alloys; (iv) adsorption onto large specific surface area-materials and (v) chemical storage in covalent and ionic compounds (formic acid, borohydrure, ammonia..) (14). Among them, compression of hydrogen is the most widespread method to store hydrogen, even if it is not the cheapest one (15). Gaseous hydrogen at high pressures is particularly used in the frame of the Haber process for ammonia production, as well as to carry out hydro-cracking of heavy petroleum fractions in order to produce lighter hydrocarbons (16).

During the last years, a significant attention has been paid to the efficient use of hydrogen in automotive applications $(17,18)$. Moreover, a "Hydrogen Economy" is often advocated as a potential way to deliver sustainable energy through the use of hydrogen (19). In this context, after being produced and before using it, hydrogen is packaged, distributed, stored and delivered, the most complex issues to solve related especially to the latter two steps (20). It has been shown that the cheapest hydrogen storage-delivery mode is obtained by compression and delivery with a truck, especially for small stations and low demands (21). For this reason, efforts have been carried out in order to improve compression solutions for hydrogen storage. It has been also shown that the introduction of new and sophisticated materials, like carbon fibre- and glass fibre-reinforced tanks, allowed a significant reduction of the storing system weight, increasing in turn the hydrogen volumetric energy density (22). Commercial vessels available nowadays achieve an average hydrogen content of 1-2 wt.\% at pressures of about 20-25 MPa (23), but composite pressure tanks up to $70 \mathrm{MPa}$ have also been successfully developed, reaching a gravimetric storage density of $6 \mathrm{wt} . \%$ and a volumetric storage density of $30 \mathrm{~g} / \mathrm{L}$ (24). These values still don't meet the two U.S. Department of Energy targets, which set the ideal gravimetric and volumetric capacity for hydrogen automotive systems to $40 \mathrm{~g} / \mathrm{L} \mathrm{v} / \mathrm{v}$ and $5.5 \mathrm{wt} \%$ for $2017(25,26)$, respectively, to be achieved in the temperature 
range 233-358 K (27). Moreover, not only the weight of the storage material but also that of the entire system should be taken into account. At present, current compression methods are unlikely to satisfy these targets (28), but at the same time they are mature enough to ensure the $70 \mathrm{MPa}$ required by the on-board hydrogen storage systems used in the Fuel Cells Vehicles as well as by the hydrogen refuelling stations (29).

The present review summarises the state of the art of the hydrogen compression technologies used for both stationary and automotive applications involving hydrogen as renewable fuel. The technical and design features, the basic operating principles and the level of performances potentially achievable for each single compressor technology are analysed, emphasising their advantages as well as their drawbacks. Specifically, their current use in hydrogen applications is described, focusing also on the technological limits and outlining the possible actions to be taken for improving their performances.

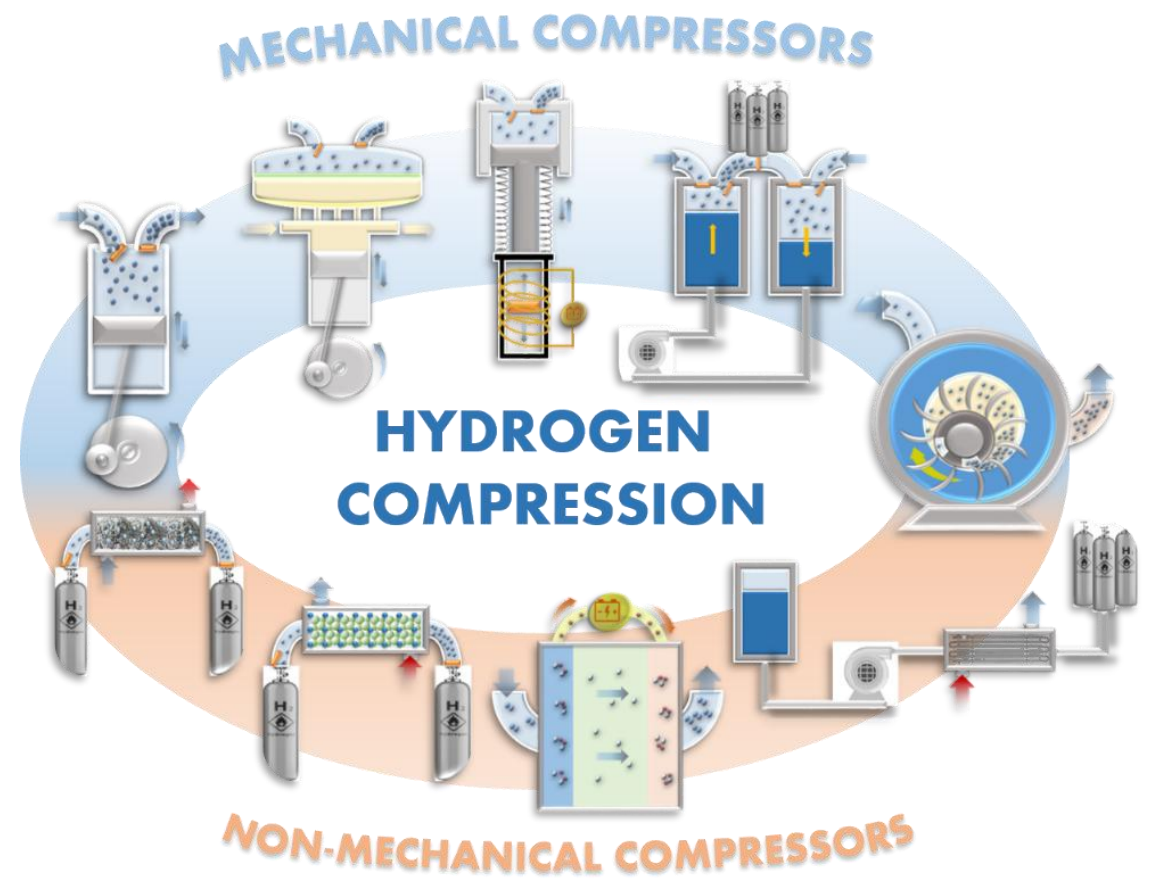

Fig. 1 - Summary of the hydrogen compression technologies currently used for stationary and automotive applications 


\section{Mechanical Compressors}

Mechanical compressors are the most widespread type of compressors used nowadays, based on the direct conversion of mechanical energy into gas energy. Among the several typologies, the "positive displacement" devices are particularly used for hydrogen compression, consisting in the reduction of the confined volume in which hydrogen is contained by the use of a piston: gaseous hydrogen is squeezed into a smaller space, so that the number of collisions among particles and with the walls increases (30), resulting in a higher gas pressure.

\subsection{Reciprocating piston compressors}

Reciprocating compressors, especially the oil-free ones, are commonly used for hydrogen applications when the desired level of pressure is higher than $3 \mathrm{MPa}$ (31). They are ideal for moderate flow and high-pressure applications: the required power consumption can be as large as 11.2 MW, with a resultant hydrogen flow as high as $890 \mathrm{~kg} / \mathrm{h}$ and a discharge pressure of $25 \mathrm{MPa}$ (15). Higher discharge pressures up to $85 \mathrm{MPa}$ are achieved by HydroPac, Inc. reciprocating hydrogen compressors, with an inlet pressure of $35 \mathrm{MPa}$ and a capacity of around $430 \mathrm{~kg} / \mathrm{h}(32)$.

Basically, a single-stage reciprocating compressor consists in a piston-cylinder system (Fig. 2), equipped with two automatic valves, one for intake and one for delivery. The piston is linked to a crankshaft through a connecting rod, converting the rotary motion of the moving units into the almost linear motion of the piston. This movement is known as reciprocating motion (33). The energy necessary for the compression is given by either an electrical or a thermal machine. The piston movement towards the upper side of the cylinder, i.e., the Top Dead Centre (TDC), creates a partial vacuum in the lower part of the cylinder itself, opening 
the intake valve and allowing the gas to enter it. The consequent suction phase lasts until the piston reaches the Bottom Dead Centre (BDC), then the intake valve is closed. Moving again towards the TDC, the gas is compressed until the pressure reaches the desired level, then the delivery valve is opened, discharging the gas.

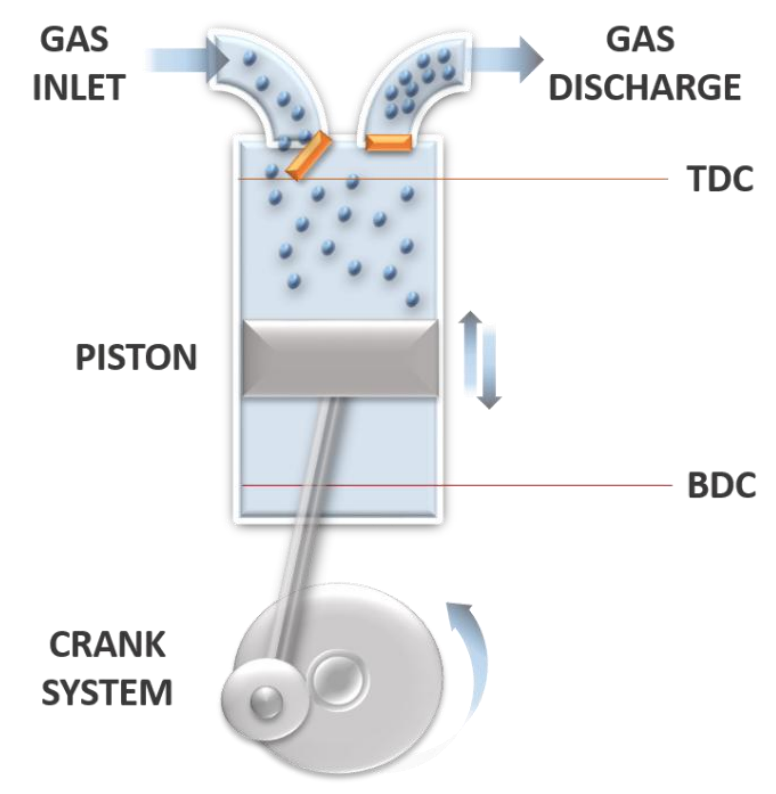

Fig. 2 - Scheme of a reciprocating piston compressor

Reciprocating compressors produce high-pressure hydrogen especially when a multistage configuration is adopted (34): a first stage of compression increases the hydrogen pressure up to a couple of atmospheres, before reaching the target value through the next stages. Actually, this configuration is particularly preferred in on-site hydrogen refuelling stations, where hydrogen is generated at a pressure around $0.6 \mathrm{MPa}$, making necessary in turn the use of an efficient compressor system in order to supply hydrogen to a fuel cell vehicle (35). On the other hand, reciprocating compressors are not efficient for high flow rates $(36,37)$. In fact, the flow rate depends on the dimension of the cylinder, as well as on the number of cycles per unit time, called speed of compression. An increase of the cylinder dimension results in bigger and heavier components, increasing in turn the inertia forces. In order to limit the resulting mechanical stresses, a decrease of speed is thus recommended. Hence, high 
compression speeds are achievable only in small cylinders, then causing a reduction of the allowable flow rates.

The embrittlement phenomena are the main drawback to overcome in hydrogen reciprocating compressors (38), making necessary a careful selection of the material used, as well as a sophisticated design. Several guidelines have to be followed, according to the API Standards 618, in which all the minimum requirements for reciprocating compressors are included (39). The cylinders, commonly made of cast iron, nodular cast iron, cast steel and forged steel (40) are covered by a liner coat, ensuring the walls protection. Being easily removable, the liner reduces repair costs in case of accident, and facilitates the adjustment of the cylinder diameter, depending on the operational requirements, thus providing an advantageous versatility to the system (41).

Since the use of lube oils can affect the durability of the compressor components, oil-free compressors are preferred, offering high performances operation and high-purity compressed gas (42). Hence, in order to prevent the contact between the piston and the cylinder (43), pistons are equipped with wear bands, usually known as rider bands, made of thermoplastic materials (44). In order to reduce as much as possible hydrogen leakages, piston rings are also used (45). Nevertheless, it has been proved that high-pressure oil-free hydrogen reciprocating compressors are particularly affected by the early failure of the sealing rings, because of a large non-uniformity of the pressure distribution inside the compression chamber (46). For this reason, a two-compartment distance piece has to be included in the design of the compressor to facilitate gas venting (39), avoiding in this way the embrittlement of the steel due to hydrogen escaped from the compression chamber.

Nowadays, the 94/9/EC European Directive concerning equipment used in potentially explosive atmospheres is also complied by the Member States of the European Union for manufacturing reciprocating compressors (47). By choosing carefully the wear materials, by 
adopting a conservative design as well as by reducing the piston speed, good performances can be reached. During the last years, better reciprocating compressors have been developed for hydrogen applications, improving significantly the operating parameters: discharge pressures of $100 \mathrm{MPa}$ and flow capacities of $300 \mathrm{Nm}^{3} / \mathrm{h}$ have indeed been reached (48).

Although reciprocating compressors are widely used for applications involving hydrogen, several limitations make them not perfectly appropriate for such purpose. Firstly, the presence of several moving parts increases the cost, because of the manufacture complexity as well as the difficulty to provide a good maintenance (49). Moreover, such typology prevents the efficient cooling of hydrogen during the compression because of the presence of moving parts, like the piston, resulting in an increase of the heat produced and in a more difficult management of thermal transfers (50). In addition, the back and forth movement of the piston causes pressure fluctuations inside the compression chamber, which can be detrimental since they may cause vibrations, noises, even explosions, and hence lead to a decrease of the system life of the overall hydrogen plant (51). Anyway, it is noteworthy that the reciprocating compressors exhibit very good performances especially when the multi-stage configuration is used, because of the high value of the discharge pressure reached and because of their flexibility in size and capacity. Several improvements have been achieved in their design, like the upgrading to non-metallic ring and valves materials, the use of a tungsten carbide piston rod coating, and the implementation of continuous monitoring systems to predict possible failures (52). However, the aforementioned drawbacks attract interest for other devices aimed at compressing hydrogen more efficiently. Table 1 gathers the main characteristics of a few representative examples of reciprocating compressors. 
Table 1 - Hydrogen reciprocating compressors

\begin{tabular}{|c|c|c|c|c|c|}
\hline \multicolumn{6}{|c|}{ RECIPROCATING COMPRESSORS } \\
\hline & $\begin{array}{c}\mathbf{P}_{\text {in }} \\
{[\mathrm{MPa}]}\end{array}$ & $\begin{array}{c}\mathbf{P}_{\text {out }} \\
{[\mathrm{MPa}]}\end{array}$ & $\begin{array}{c}\text { Flow } \\
{\left[\mathrm{Nm}^{3} / \mathrm{h}\right]}\end{array}$ & Applications & $\begin{array}{c}\text { Efficiency } \\
{[\%]}\end{array}$ \\
\hline Leonard S. M. (52) & 0.4 & 25.5 & no data & $\begin{array}{l}\text { - Catalytic reformers } \\
\text { - Hydrogen plants }\end{array}$ & no data \\
\hline Amos W. A. (15) & no data & 25 & $\sim 10000$ & - Compressed gas storage & no data \\
\hline Kurita et al. (35) & 0.6 & 70 (5 stages) & no data & $\begin{array}{l}\text { - Hydrogen refuelling } \\
\text { stations }\end{array}$ & no data \\
\hline Hydropac (32) & 35 & 85.9 & 4820 & $\begin{array}{l}\text { - Filling vehicle tanks } \\
\text { - Moving gas between } \\
\text { storage vessels }\end{array}$ & no data \\
\hline $\begin{array}{l}\text { Hitachi } \\
\text { Infrastructure } \\
\text { System (48) }\end{array}$ & 0.6 & 100 & 300 & - Hydrogen stations & no data \\
\hline Advantages & \multicolumn{5}{|c|}{$\begin{array}{l}\text { - Mature technology } \\
\text { - Adaptability to a large range of flow rates } \\
\text { - High discharge pressures }\end{array}$} \\
\hline Disadvantages & \multicolumn{5}{|c|}{$\begin{array}{l}\text { - Contamination by lube oils (if used) } \\
\text { - Embrittlement phenomena } \\
\text { - Several moving parts } \\
\text { - Manufacturing complexity } \\
\text { - Difficulty to provide good maintenance } \\
\text { - Difficulty in managing the thermal transfer } \\
\text { - Presence of vibrations and noise }\end{array}$} \\
\hline
\end{tabular}

No data means that the information was not provided in the corresponding references.

\subsection{Diaphragm compressors}

Thanks to their high throughput, lower power consumption and low cooling requirements, diaphragm compressors have been proved to be very effective for hydrogen applications (53). Generally, they fit well when highly chemically pure gases have to be handled, since the direct contact between the gas and the piston is prevented (54)(55). In fact, the gas is completely isolated from the piston, since its movement is transmitted to a hydraulic fluid, which in turn transmits the motion to a thin metal membrane called "diaphragm", isolating hydrogen from the hydraulic part. The forth movement of the diaphragm into the cavity space, in which the gas is confined, reduce the available volume, thereby allowing an increase of the gas pressure (Fig. 3). 


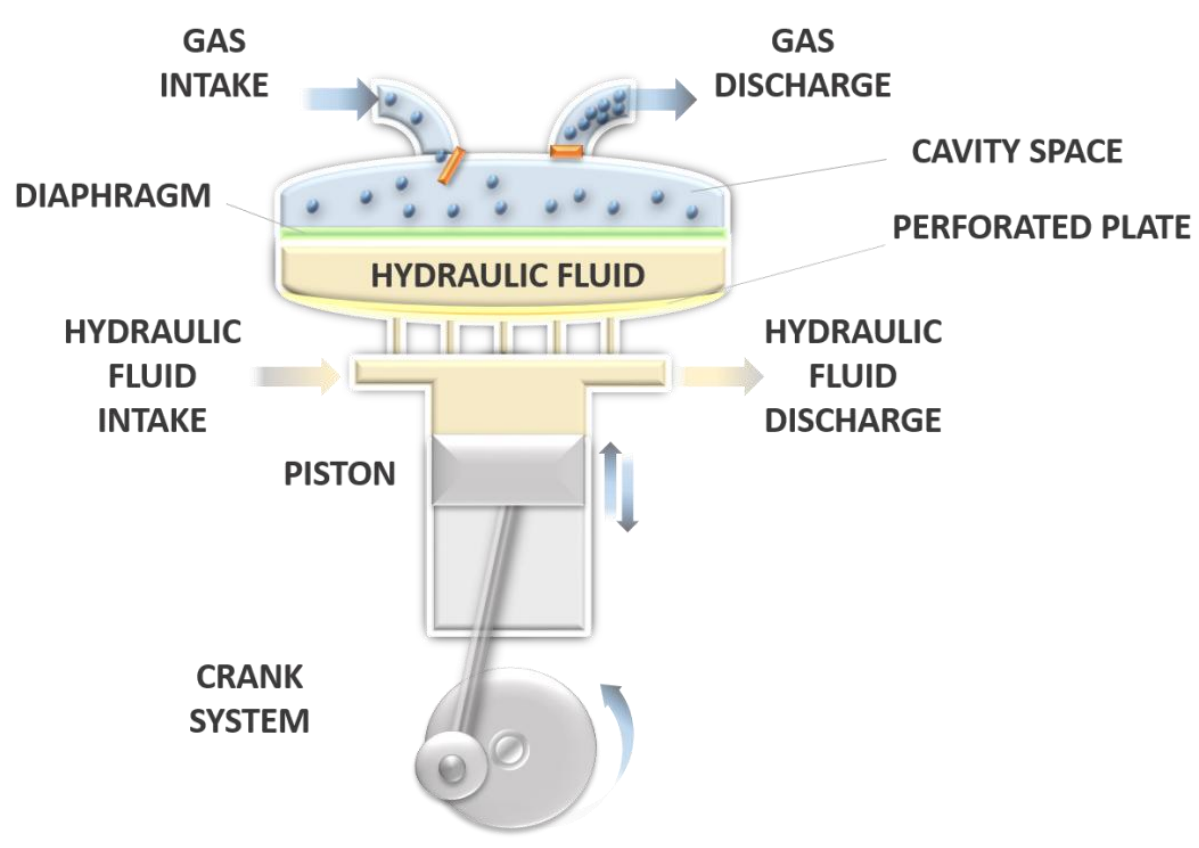

Fig. 3 - Scheme of a metal diaphragm compressor

Actually, the diaphragm is composed of three different plates (56): (i) the process plate, on the hydrogen side, coming in contact exclusively with it; (ii) the hydraulic plate, on the hydraulic fluid side and (iii) the middle plate, set between the former two units, with the purpose of detecting eventual leaks and avoiding the diaphragm failure.

The hydraulic fluid in a diaphragm compressor is essentially oil. Whereas in reciprocating compressors oil could be used exclusively for lubricating purposes, in the diaphragm typology it directly controls the diaphragm movement (57). A specific hydraulic circuit provides oil to the hydraulic space (57), and is equipped with a hydraulic pressure limiter monitoring the pressure level beneath the diaphragm. A perforated plate acts as oil distributor, in order to achieve a uniform pressure load on the diaphragm plates. The oil pressure control is crucial in order to obtain good efficiencies, since once the gas is discharged and the diaphragm group is completely deflected in the discharge position, the piston still has to reach its TDC position. As a consequence, the pressure inside the oil space increases, becoming higher than the gas discharge pressure. Hence, the hydraulic pressure limiter is opened at a value slightly higher 
than the one set for the gas discharge, reducing the eventual liquid-gas pressure differential across the diaphragm and thus increasing the service lifetime of the whole system (58). The presence of a separate circuit for the compressing oil makes also possible the integration of a cooling system, so that the heat produced during the compression step can be effectively withdrawn (59).

Since the diaphragm is in contact at the same time with hydrogen on one side and with oil on the other side, a careful selection of the building materials is of key importance (60), with respect to the basic requirements of high corrosion resistance and high durability. Stainless steel, stainless chrome nickel steel, alloys from copper-beryllium and duplex steel are the materials commonly used for the diaphragm plates (61). Diaphragm compressors acts properly to minimise the hydrogen leakages, since the hydrogen circuit is a closed loop well separated from the oil one, with the result that the purity of the gas is kept always very high (62). This feature seems to be crucial considering that hydrogen leakages affecting the mechanical compressors are the primary risk factor in hydrogen refuelling stations (63).

Diaphragm compressors are able to reach very high volumetric efficiencies, which are beneficial for energy saving (64). However, one of the most important drawbacks of this kind of compressors is related to their durability, as they are weakened by the mechanical stresses during operation. Since too high flow rates can cause the early failure of the diaphragm, a good design includes concavities and grooves ensuring proper flow distributions (65). Diaphragm compressors are appropriate especially for applications requiring low flow rates (66), due also to the limited volume of the compression chambers commonly employed (67). Diaphragm failure can be also caused by the radial stresses related to the diaphragm deflection (68), and strictly correlated to the geometry of the cavity space in which it moves. Further stresses can arise from the contact between the diaphragm and the perforated plate (63), causing fractures on the edge of the diaphragm and hence compromising the overall 
compressor operation. Hence, new designs of the diaphragm plates have been proposed by numerical simulation models (69-71).

The high efficiency, compactness, good scalability and absence of complex sliding mechanisms make the diaphragm compressors well-suited even for microscale applications (72). With the recent development of the microelectromechanical systems (MEMS), the demand for micro-compressors considerably increased, and efforts are being focused on their development (73). For instance, a MEMS based on an innovative electrostatic diaphragm compressor has been developed (74). Instead of using the motion of a piston, the compression is produced by a dc voltage applied between the edges of the compression chamber and the diaphragm by means of metal electrodes (Fig. 4). The electric field generated in the chamber forces the diaphragm to move towards the surface on which the voltage is applied, and the resultant volume reduction increases the gas pressure. The polarity of the applied voltage is varied cyclically, allowing the gas compression in both halves of the cavity space. In order to avoid electric shorting when the diaphragm comes in contact with the surfaces of the chamber, dielectric coating layers are deposited on the top of the metallic electrodes (75).

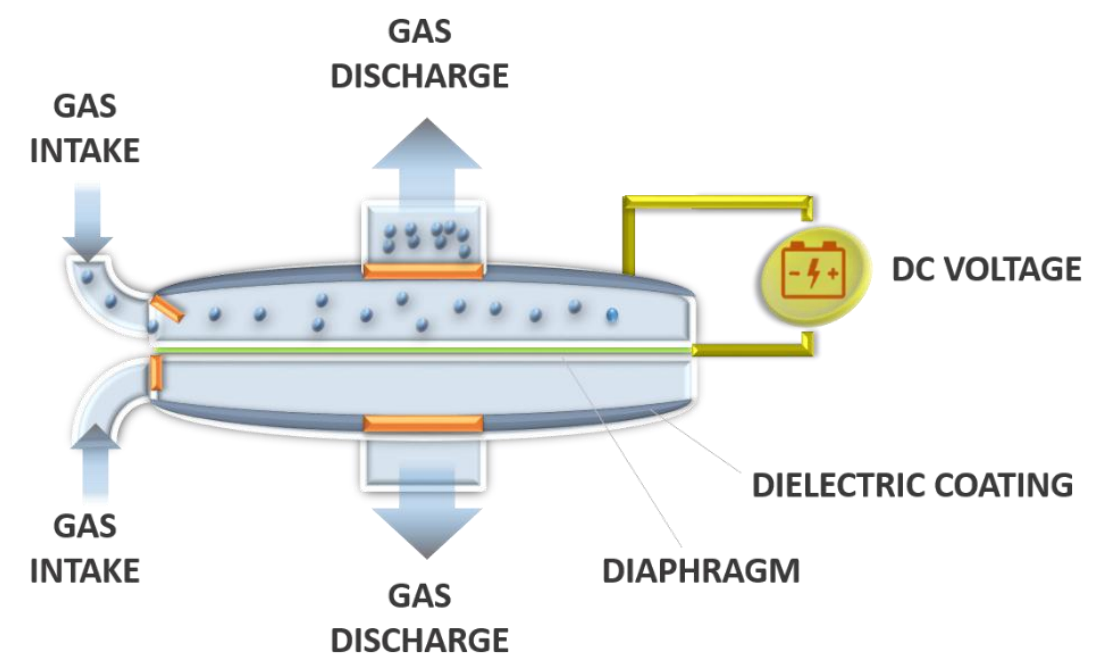

Fig. 4 -Scheme of an electrostatic diaphragm compressor 
Electrostatic diaphragm compressors might offer a good solution for hydrogen compression in small size facilities, even though today traditional compressors remain the most used. The German company Hofer Hochdrucktechnik (61), well-known worldwide for their hydrogen diaphragm compressors, has equipped several hydrogen refuelling stations compressing the gas at around $390-581 \mathrm{Nm}^{3} / \mathrm{h}$ with a discharge pressure up to $28.1 \mathrm{MPa}(61)$. On the other hand, the American company PDC machines (76) is leader in manufacturing diaphragm hydrogen compressors for fuel cells vehicles; these compressors operate at a discharge pressure of $51.7 \mathrm{MPa}$ and flow rates from 50 to $280 \mathrm{Nm}^{3} / \mathrm{h}$.

Even though diaphragm compressors exhibit several advantages, on average, one of the most compelling goals is currently the optimisation of the diaphragm design in order to reduce its risk of failure. Achieving this goal could mean the realization of efficient hydrogen vending stations, reaching the DOE's target of implementing a strong hydrogen distribution network (77). Table 2 gathers the main characteristics of a few representative examples of hydrogen diaphragm compressors.

Table 2 - Hydrogen diaphragm compressors

\begin{tabular}{|c|c|c|c|c|c|}
\hline \multicolumn{6}{|c|}{ DIAPHRAGM COMPRESSORS } \\
\hline & $\begin{array}{c}\mathbf{P}_{\text {in }} \\
{[\mathrm{MPa}]}\end{array}$ & $\begin{array}{c}\mathbf{P}_{\text {out }} \\
{[\mathrm{MPa}]}\end{array}$ & $\begin{array}{c}\text { Flow } \\
{\left[\mathrm{Nm}^{3} / \mathrm{h}\right]}\end{array}$ & Application & $\begin{array}{c}\text { Efficiency } \\
{[\%]}\end{array}$ \\
\hline \multirow{7}{*}{ Hofer (61) } & 0.5 & 15.1 & 5.5 & no data & no data \\
\hline & 0.9 & 9.7 & 390 & no data & no data \\
\hline & 1.1 & 25.1 & 112 & no data & no data \\
\hline & 1.8 & 28.1 & 581 & no data & no data \\
\hline & 2.6 & 18 & 450 & no data & no data \\
\hline & 2.8 & 9.7 & no data & no data & no data \\
\hline & $3-3.5$ & $4.77-4.84$ & 556 & no data & no data \\
\hline PDC Machines (76) & no data & 51.7 & $50-280$ & $\begin{array}{l}\text { - Hydrogen fuel } \\
\text { cells vehicles }\end{array}$ & no data \\
\hline Weinert et al. (78) & 1.3 & 43 & no data & $\begin{array}{l}\text { - Hydrogen } \\
\text { refuelling stations }\end{array}$ & 65 \\
\hline Tzimas et al. (66) & no data & 100 & $200-700$ & no data & $80-85$ \\
\hline Advantages & \multicolumn{5}{|c|}{$\begin{array}{l}\text { - High throughput } \\
\text { - Low power consumption } \\
\text { - Low cooling requirement } \\
\text { - Ideal for handling pure gases or explosives }\end{array}$} \\
\hline Disadvantages & \multicolumn{5}{|c|}{$\begin{array}{l}\text { - Diaphragm failure } \\
\text { - Complex design }\end{array}$} \\
\hline
\end{tabular}




\subsection{Linear compressors}

Linear compressors are particularly used in cryogenic applications driven by Stirling cycle coolers and involving hydrogen and helium gas $(79,80)$, as well as for domestic refrigeration (81). Compared to the former mechanical compressors, the piston is directly connected to a linear motor coupled with a resonating spring system (Fig. 5), reducing the number of moving units because of the absence of rod-crank assembly.

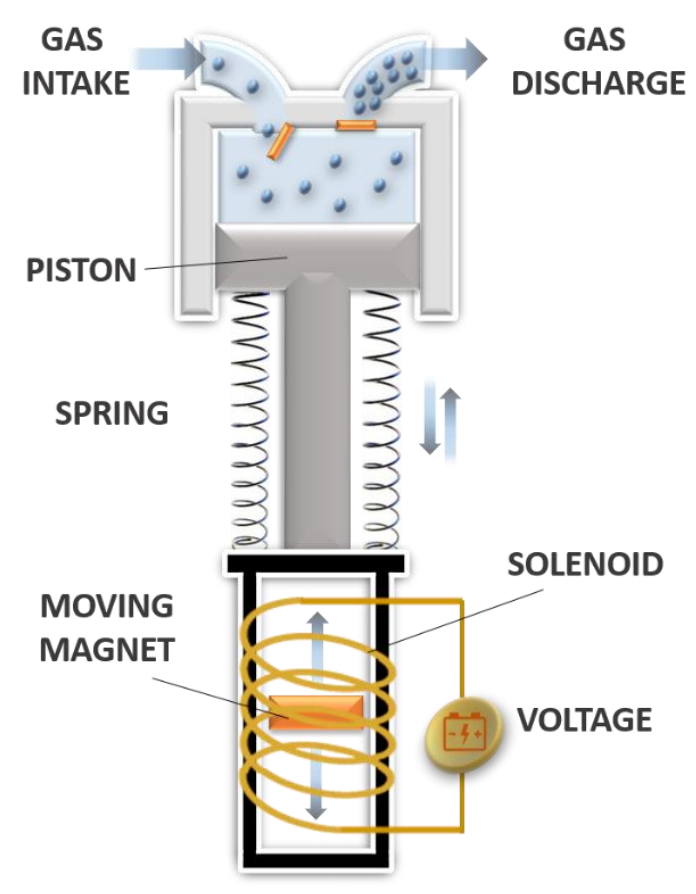

Fig. 5 - Scheme of a linear compressor

The low number of rotating components makes the arrangement of the whole system simpler with regards to the aforementioned compressors, leading at the same time to significant cost savings (82). Nevertheless, for stationary, industrial and automotive applications, there are no references about the use of linear compressors for hydrogen applications, being considered as an innovative way to compress hydrogen since a few years only (62). 
The targets set by the US Department of Energy (DOE), focused on the increase of the compression efficiency as well as on the cost reduction of hydrogen compressors, have made linear compressors very attractive. The design of linear compressors is consolidated nowadays, and several thermodynamic studies have deepened the overall knowledge of this technology during the last years (83). The linear motors commonly used for driving the piston are magnetic-type, and more specifically moving-coil (84-86) and moving-magnet types (85). The Oxford moving-coil linear motor has been used for a long time, especially in aerospace applications, because of its high efficiency, low vibration, low noise emissions and long operation life (87). Basically, this motor consists of a series of hollow coils moving only in the axial direction and immersed in a radial strong magnetic field. Despite their structural simplicity, moving-coil motors require large amounts of permanent magnets to achieve high efficiencies. The moving-magnet motor therefore seems to be the best alternative, exhibiting high reliability, low material outgassing rate and a good thermal dissipation (88). This motor is composed of a permanent magnet divided in two separate parts, in the middle of which a moving magnet directly controls the axial movement of the piston (89), providing high magnetic fluxes with only a small amount of magnets (90). By inverting the polarity of the voltage applied to the magnet through the use of electronic circuits or inverters, the direction of the piston stroke is thus inverted, allowing both expansion and compression steps.

Magnetic motors for linear compressors are designed to work at the mechanical resonance frequency, so that the required energy for the piston displacement is transferred without large driving forces (91), thereby minimising the driving electric current as well as the Joule losses in the coil. Linear compressors work at the mechanical resonance when their operating frequency is set to the natural frequency value (92), and by doing such frequency adjustment, very high efficiency levels can been achieved (93). If the working frequency deviates from the resonance value, the system is no longer able to work in the optimum conditions: for this 
reason, an additional control system for the frequency is required. The resonance frequency of the compressor can be obtained from the following equation (94):

$$
\omega_{\text {resonance }}=\sqrt{\frac{k_{\text {gas }}+k_{\text {mechanic }}}{m}}
$$

where $k_{\text {gas }}$ is the stiffness of the gas spring, $k_{\text {mechanic }}$ is the axial stiffness of the mechanical springs and $m$ is the moving mass. The stiffness of the gas spring can be obtained from the Hooke's law by considering the gas like a spring pulling and pushing the piston (87), whereas the stiffness of the mechanical springs is a function of their length, width and thickness. Actually, the evaluation of the resonant frequency is not easy, because of the nonlinearity affecting the gas spring, varying continuously throughout the operation (95).

A clear advantage in using linear compressors is that the piston and the cylinder are separated by a gas bearing system (86), consisting in driving back into the compression chamber an established amount of high-pressure gas, which acts as a pad avoiding frictions. Moreover, this is beneficial for hydrogen applications since no oil lubes are used and the resultant discharge gas exhibits a high-purity level. In addition, this allows linear compressors to generate less than half of $\mathrm{dB}$ than the reciprocating ones (96), resulting in very silent operations. However, gas bearings induce piston drift because of oscillating pressure on the side of the compression chamber side and almost constant pressure on the side of the motor body (97).

The absence of a rod-crank assembly in the linear compressors involves that the piston movement can be easily affected by several factors like temperature, supply voltage and gas flow, making necessary the use of a position control device (84). Actually, this might be an advantage, since it would be possible to optimise the piston position when necessary, allowing reaching optimum performances with a certain versatility. However, the control system design 
is not simple. In some works $(97,98)$, an inductive position sensor consisting in a sophisticated coil assembly was used to monitor the piston displacement, but since this method was very complex and expensive, indirect methods should be considered, like the continuous manipulation of the supplied voltage (99).

Nowadays, linear compressors are especially used for electronics cooling, thanks to their own capacity in maintaining low temperatures inside chips and miniature devices (100). Nevertheless, the Southwest Research Institute (Texas) investigates a novel concept to enhance their applicability for high-scale hydrogen applications, consisting in driving a permanent magnet piston inside a hermetically-sealed compressor cylinder through electromagnetic windings (82). The main purpose is to obtain hydrogen at around $87.5 \mathrm{MPa}$ through a system consisting of three linear compressors combined with a water-based cooling loop (Fig. 6). Table 3 gathers the main characteristics of a hydrogen linear compressor.

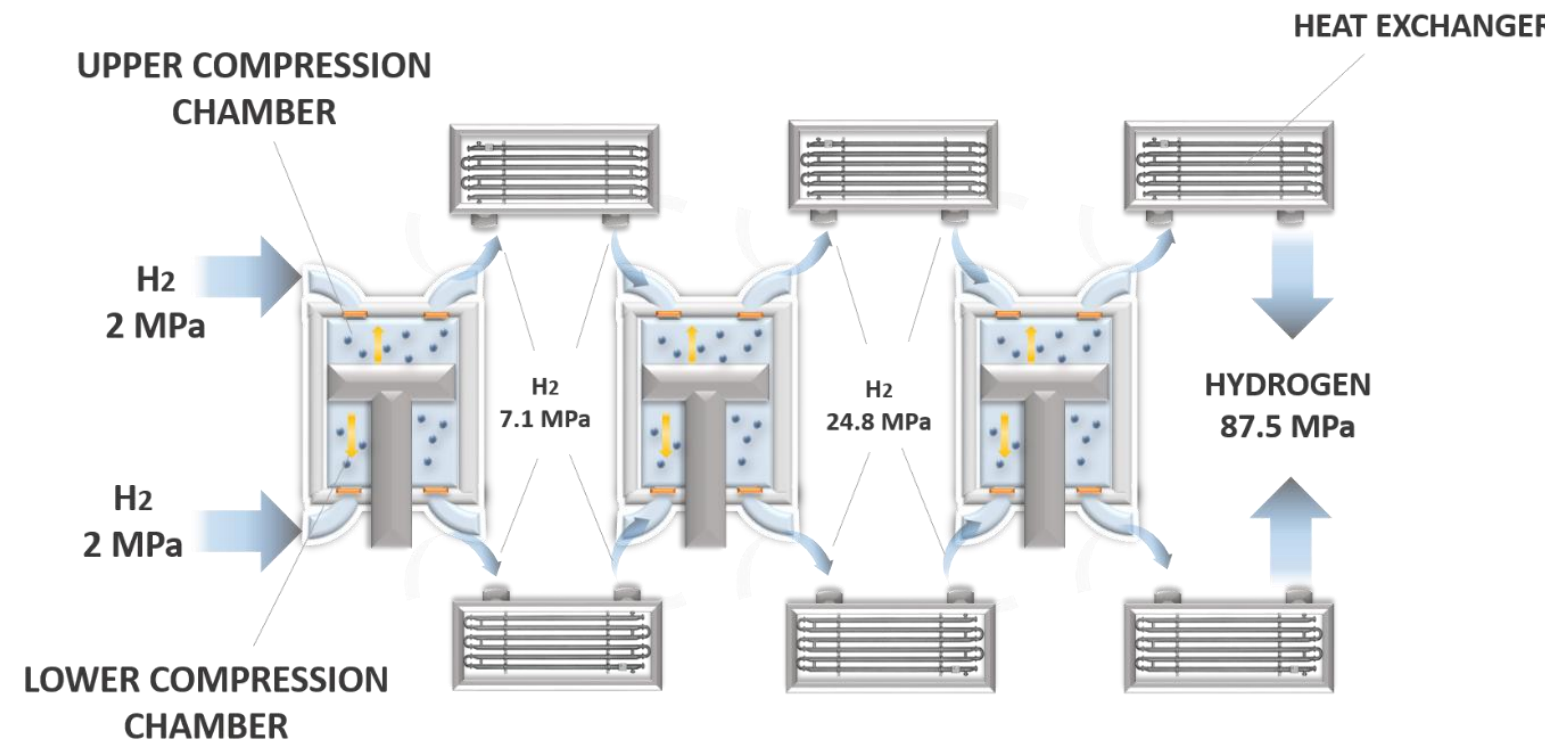

Fig. 6 - Scheme of a three-stage linear compressor system for hydrogen applications (After $(82))$ 
Table 3 - Hydrogen linear compressor

\begin{tabular}{|c|c|c|c|c|c|}
\hline \multicolumn{6}{|c|}{ LINEAR COMPRESSOR } \\
\hline & $\frac{\mathbf{P}_{\text {in }}}{[\mathrm{MPa}]}$ & $\begin{array}{c}\mathbf{P}_{\text {out }} \\
{[\mathbf{M P a}]}\end{array}$ & $\begin{array}{c}\text { Flow } \\
{\left[\mathrm{Nm}^{3} / \mathrm{h}\right]}\end{array}$ & Application & $\begin{array}{c}\text { Efficiency } \\
{[\%]}\end{array}$ \\
\hline $\begin{array}{c}\text { Broerman et al. } \\
(82)\end{array}$ & 2 & $\begin{array}{c}86-95 \\
(3 \text { stages })\end{array}$ & $>112$ & - Research studies & $>73^{*}$ \\
\hline Advantages & \multicolumn{2}{|c|}{$\begin{array}{l}\text { - Compactness } \\
\text { - High reliability } \\
\text { - High efficiency }\end{array}$} & & \multicolumn{2}{|c|}{$\begin{array}{l}\text { - Low vibration and low noise } \\
\text { - Long operation life } \\
\text { - Only few moving parts }\end{array}$} \\
\hline Disadvantages & \multicolumn{5}{|c|}{$\begin{array}{l}\text { - Necessity to control the piston displacement } \\
\text { - Necessity to operate at resonant conditions } \\
\text { - Oscillating pressure }\end{array}$} \\
\hline
\end{tabular}

\subsection{Liquid compressors}

Liquid compressors are particularly suitable for hydrogen applications (49). They are positive displacement devices (101) using liquids for directly compressing a gas (102), working in the absence of mechanical sliding seals. They are widely recognised to achieve inexpensive compression, since they are able to ensure a quasi-isothermal process (103-105). In fact, the liquid and the gas are compressed together, but since the liquid has a higher density as well as a higher heat capacity, the heat generated by compression is efficiently absorbed by the liquid and by the surrounding walls of the compression chamber. In addition, the resultant thermal management through the liquid itself prevents the use of external heat exchangers, thus reducing the cost of the overall system. As a result, such typology of compression has a significant advantage over the other mechanical compressors in terms of efficiency, with values higher than $83 \%$ (102).

\subsubsection{Liquid piston compressors}

Like in all other mechanical compressors typologies, hydrogen confined in a closed space is directly compressed by a moving piston, which in the present devices is liquid (106). 
Specifically, a column of liquid moves forth and back in a cylinder, compressing the gas introduced in its head. The liquid movement is driven by a pump, which in most of applications is connected to two cylinders, where a compression step continually follows an expansion step (Fig. 7).

Liquid piston compressors are especially used in the context of compressed air energy storage, in which electrical power is converted into compressed air energy at 20-30 MPa (107), and which can be used on site to power generators and turbines, or can be stored for being used later. This kind of solution is usually associated with renewable energy plants $(105,108-110)$. Porous media can be used in order to improve significantly the heat transfer inside the compressor chamber $(105,111,112)$. Since the liquid can flow through the open, connected pores of the porous matrix, an increase of the overall heat capacitance is achieved, limiting the temperature rise of the gas. Moreover, the presence of porous solids ensures at the same time a good seal to prevent gas leakages, eliminating potential dead volumes and increasing the efficiency (105).

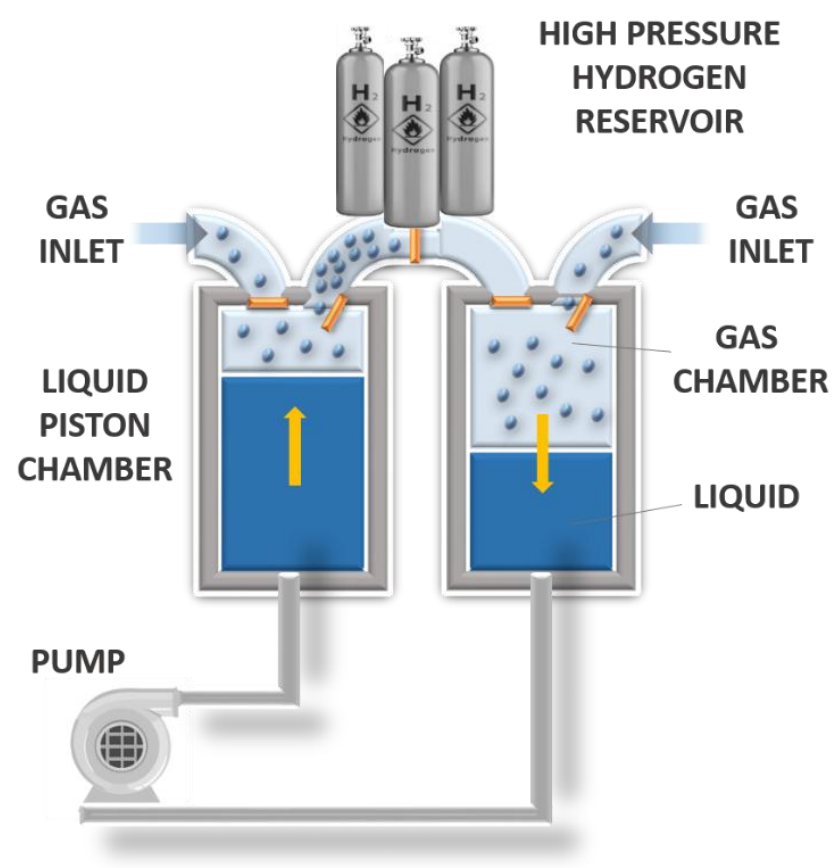

Fig. 7 - Scheme of a liquid piston compressor 
Internal liquid-spray cooling, usually adopted in reciprocating compressors, can even be a valid alternative to further limit the temperature rise inside the compression chamber (113), as the liquid droplets provide a large surface area for the heat transfer, absorbing efficiently the heat generated by the compression process. Moreover, liquid piston compressors benefit more than the reciprocating ones from this cooling method, since the residue of the spray falls downwards to the liquid phase. However, in order to obtain an effective increase of compression efficiency, an optimal spray profile has to be determined (114).

\subsubsection{Liquid rotary compressors}

Liquid rotary compressors (Fig. 8) are particularly used for compressing a gas with a high liquid content $(54,115,116)$. In this design, an impeller located eccentrically in a stator frame and composed of a series of blades extended radially from it, forces the liquid to move globally in an oscillatory manner, forming a ring compressing the gas introduced from a door placed in the rotor centre (116)(117). This kind of compressor fits very well applications implying vacuum (118), or when saturated gases have to be handled (119). However, they are not widely used because of their low overall efficiency, about 50\% (116).

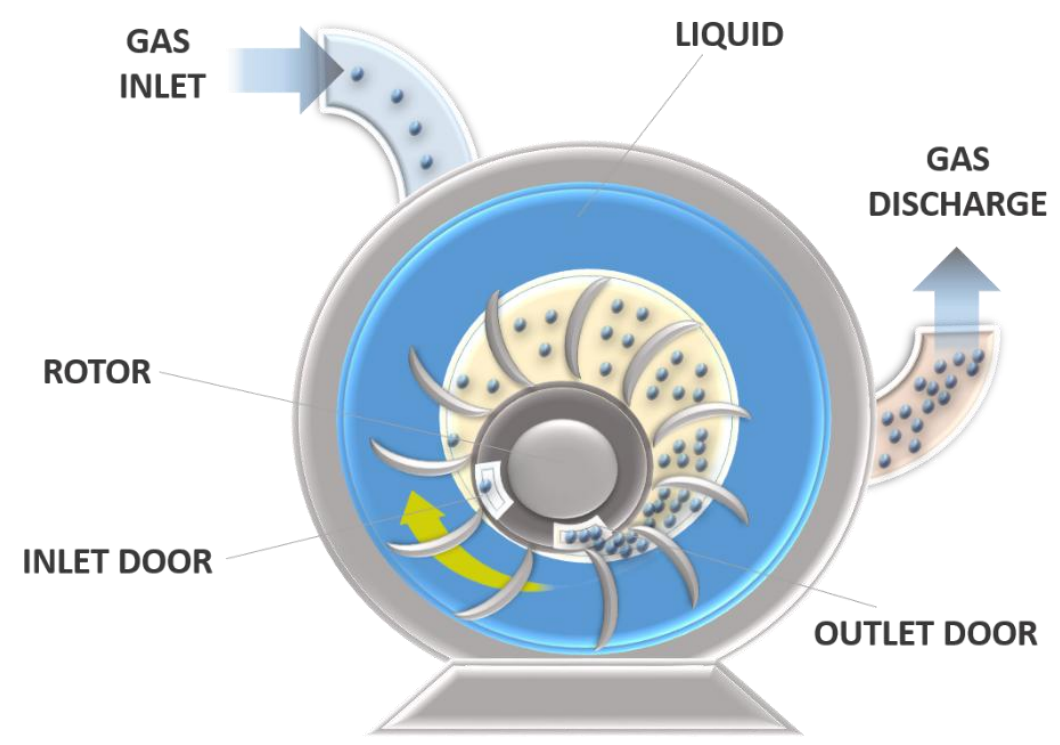

Fig. 8 - Scheme of liquid rotary compressor 


\subsubsection{Ionic liquid compressors}

Ionic liquid compressors were specifically developed for increasing the compression efficiency when hydrogen is used (67). Ionic liquids are low-melting point salts, hence in the molten state at room temperature (120), exhibiting good thermal and chemical stability, high ionic conductivity, fire retardance, moderate viscosity, high polarity, negligible volatility, no negative effect on human health, as well as low compressibility and superior lubricating abilities especially for high-pressure applications $(121,122)$. They are interesting for a broad range of energy applications, e.g. in batteries, fuel cells, solar cells and thermal storage (123). When used for compression applications, by substituting the solid piston in a positive displacement device as well as in rotary configurations, the ionic liquids ensure very good performances, thanks not only to their intrinsically low vapour pressure, but also to their excellent tribological behaviour as well as to the very low solubility of most gases into them (124). Specifically, hydrogen solubility in many ionic liquids is negligibly low (125), achieving in this way very high volumetric efficiencies and high compression ratios (126).

Ionic liquids compressors for hydrogen applications have been developed in particular by the International German Company Linde $(127,128)$. Linde ionic compressors need only eight moving units to ensure good performances, which is clearly less than in reciprocating compressors, reducing in turn the mechanical losses and improving the overall efficiency. Hydrogen is compressed up to $90 \mathrm{MPa}$ in only five steps, with an efficiency that is increased thanks to the good lubricant and coolant properties of the ionic liquids. It is noteworthy that no lube oils are used so that hydrogen is not polluted; this is a great advantage especially in fuel cells applications.

Ionic liquid compressors used in hydrogen fuelling stations were proved to be a highperformance solution for the enhancement of the hydrogen value chain (128). When compared with a lubricant-free reciprocating compressor, the net capacity was indeed 
increased from 5-11 kg/h to $8-30 \mathrm{~kg} / \mathrm{h}$, with a final pressure increased from $35-70 \mathrm{MPa}$ to $45-$ $90 \mathrm{MPa}$ (127). The use of ionic liquids for hydrogen compression also ensures low energy consumption, long service life, low material costs and low noise emission. Nevertheless, the risk of corrosion remains high, causing a decrease of the overall efficiency by reducing the strength of the constituting materials and increasing the possibility of contamination by the corrosion products. Besides, an increase of the maintenance costs is to be expected. It has been found that the stainless steel AISI $316 \mathrm{~L}$ is particularly well-suited for hydrogen ionic liquid compressors (129), preventing corrosion effects as well as hydrogen embrittlement phenomena. In addition, other drawbacks can impair the performances of ionic liquid compressors: (i) the liquid may leave the compression chamber through the discharge line together with the gas, making necessary the use of liquid traps in the gas passage (102); and (ii) a certain amount of gas can be driven in the liquid, causing cavitation phenomena in the low-pressure areas of the cylinder (104). Table 4 gathers the main characteristics of a few representative examples of hydrogen ionic liquid compressors.

Table 4 - Hydrogen ionic liquid compressors

\begin{tabular}{|c|c|c|c|c|c|c|}
\hline \multicolumn{7}{|c|}{ IONIC PISTON COMPRESSORS } \\
\hline & $\begin{array}{c}\mathbf{P}_{\text {in }} \\
{[\mathrm{MPa}]}\end{array}$ & $\begin{array}{c}\mathbf{P}_{\text {out }} \\
{[\mathrm{MPa}]}\end{array}$ & \multicolumn{2}{|c|}{$\begin{array}{c}\text { Flow } \\
{\left[\mathbf{N m}^{3} / \mathbf{h}\right]}\end{array}$} & Application & $\begin{array}{c}\text { Efficiency } \\
{[\%]}\end{array}$ \\
\hline Van de Ven (102) & no data & no data & \multicolumn{2}{|c|}{ no data } & no data & 83 \\
\hline \multirow{2}{*}{$\begin{array}{c}\text { The Linde Group } \\
\qquad(\mathbf{1 2 7 , 1 2 8 )}\end{array}$} & no data & $45-90$ & \multicolumn{2}{|c|}{$\sim 90-340$} & $\begin{array}{l}\text { - Hydrogen } \\
\text { refuelling station }\end{array}$ & $>65 \% *$ \\
\hline & $0.5-20$ & 100 & \multicolumn{2}{|c|}{$376-753$} & $\begin{array}{l}\text { - Hydrogen } \\
\text { refuelling station }\end{array}$ & no data \\
\hline Advantages & \multicolumn{3}{|c|}{$\begin{array}{l}\text { - High efficiency } \\
\text { - High compression factors } \\
\text { - Low energy consumption } \\
\text { - Reduced wear and long service life } \\
\text { - Low material costs }\end{array}$} & \multicolumn{3}{|c|}{$\begin{array}{l}\text { - Low noise emission } \\
\text { - Quite isothermal compression } \\
\text { - No gas contamination } \\
\text { - Very small number of moving parts }\end{array}$} \\
\hline Disadvantages & \multicolumn{6}{|c|}{$\begin{array}{l}\text { - Liquid leaks } \\
\text { - Cavitation phenomena } \\
\text { - Corrosion }\end{array}$} \\
\hline
\end{tabular}

*this value was calculated by considering the specific energy consumption of this compressor provided in the corresponding reference $(2.7 \mathrm{kWh} / \mathrm{kg})$ and by considering the compression process as isothermal 


\section{Non-mechanical compressors}

Even though mechanical compressors have been widely used for hydrogen applications, the low specific volumetric energy density affecting hydrogen in the gaseous state requires significant amounts of energy for compressing enough gas (130): the actual work of compression carried out by a mechanical hydrogen compressor is almost one-third of the amount of energy stored in the resultant compressed gas (131). Moreover, the efficiency of a mechanical hydrogen compressor is still modest in low-power applications (132). A possible solution might be storing hydrogen at cryogenic temperatures since the volumetric energy density is higher, but due to the high cost as well as to the difficult thermal management, this method is reserved for special applications only. Thermally-driven compressors have also shown to be a good alternative, as well as the electrochemical compressors.

\subsection{Cryogenic compression}

Cryo-compression combines hydrogen liquefaction and compression, providing a combination of benefits and challenges of both storage methods, relying on the achievement of high pressures at very low temperatures. High-pressure hydrogen is obtained by using cryogenic pumps able to reach a discharge pressure as high as $85 \mathrm{MPa}$, a hydrogen flow rate of $100 \mathrm{~kg} / \mathrm{h}$ and a hydrogen density up to $80 \mathrm{~g} / \mathrm{L}$ (133). Hence, instead of compressing hydrogen in the gaseous state, liquid hydrogen is pressurised (134) and stored in cryocompression systems consisting of a pressure vessel integrated in an insulated jacket to significantly reduce the heat transfers between cold hydrogen and the exterior (135). The inner vessel is generally made of carbon-fibre-coated metal, the intermediate vacuum space filled with sheets of highly reflective metallized plastic, and the outer jacket made of metal (136). A cryo-compressed hydrogen vessel fuelled by liquid hydrogen at high pressure offers 
several advantages when compared to the traditional cryogenic tanks storing liquid hydrogen at ambient pressure, such as (i) lower evaporative losses due to short periods of inactivity or low driving distances, and (ii) smaller ullage spaces (up to 20\%) to prevent dangers (137). This solution allows storing 2-3 times more fuel than using conventional ambient-temperature compressed vessels (138), i.e., a lower pressure is necessary to store a given amount of hydrogen. Whereas a pressure of $75 \mathrm{MPa}$ is indeed necessary for storing $4.1 \mathrm{~kg}$ of hydrogen in $100 \mathrm{~L}$ at room temperature, a pressure of only $15 \mathrm{MPa}$ is required to compress the same amount when the temperature is decreased to $77 \mathrm{~K}$ (139) (140).

The design of such hydrogen-compressing system is very sophisticated, and consists into several modular elements sequentially arranged, i.e., a tank storing liquid hydrogen at low pressure, a cryogenic pump, and cryo-compressed vessels. Liquid hydrogen is fed to a cryogenic pump through vacuum-insulated piping. Then, the cryo-pump leads liquid hydrogen to the desired pressure value. Vaporisers can be used downstream of the cryogenic pump in order to obtain high-pressure gaseous hydrogen (141), as shown in Fig.9.

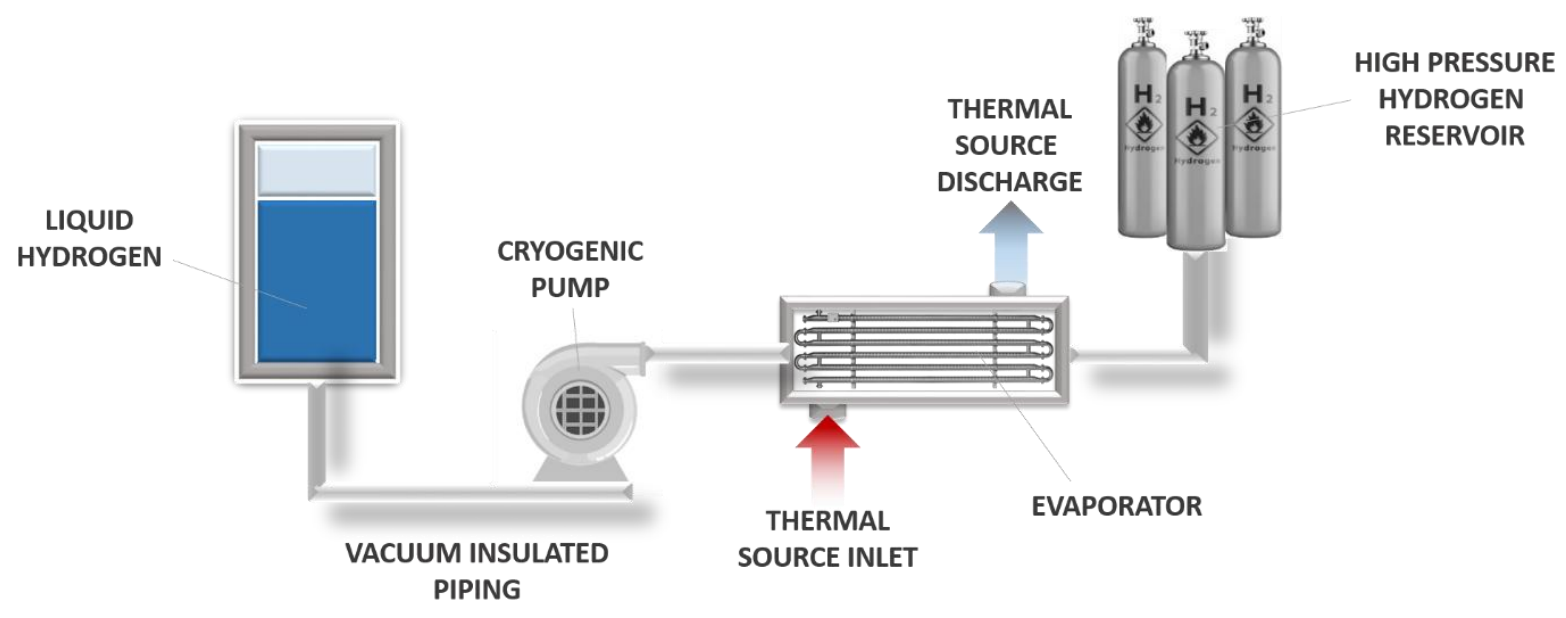

Fig. 9 - Scheme of a cryogenic hydrogen compressor system 
Hydrogen cryo-compression systems have more than twice the volumetric efficiency of a mechanical system (142). Nevertheless, the low temperatures require a continuous monitoring of the system thermal insulation, with a resulting higher system complexity aimed to control the vacuum stability $(136,143)$, which represents the greatest technological challenge (136). The performances of such a system strictly depend on the geometry of the pressure vessel, as well as on the materials used. Several improvements were achieved during the last years, such as a significant compaction of the overall system package (139) or a reduction of the liner thickness, from 3 to $1.5 \mathrm{~cm}$ (142). Further improvements could be also achieved using lighterdensity alloys as shell materials: a nominal hydrogen storage capacity of 9.2 wt.\% was reached when an $\mathrm{Al}$ alloy was used.

Cryo-compressed hydrogen vessels have been tested especially for automotive applications, e.g. the hybrid ICE/battery Toyota Prius and several prototypes proposed by BMW $(144,145)$. Hydrogen cryo-compression meets DOE 2017 system targets, thus fostering the development of cryo-compressed hydrogen storage for automotive applications (146). Moreover, hydrogen cryo-compression allows reaching $70 \mathrm{MPa}$, necessary for the development of an efficient hydrogen refuelling station (31). Supercritical cryo-compressed hydrogen storage for fuel cell-powered electric buses was also investigated (147). Using a 50 MPa cryo-compressed hydrogen vessel, an improvement of $91 \%$ in gravimetric capacity was achieved. A reduction of $46 \%$ in carbon fibre composite mass and $21 \%$ lower system cost than in the case of a $35 \mathrm{MPa}$ composite vessel filled with gaseous hydrogen were also obtained (147). The cost of a $35 \mathrm{MPa}$ hydrogen vessel is around $17 \$ / \mathrm{kWh}$ while the cryocompressed counterpart costs around $14 \$ / \mathrm{kWh}$. Nevertheless, the cost of a cryogenic hydrogen storage system still remains much higher than the DOE targets $(4 \$ / \mathrm{kWh})(139)$.

Beside the aforementioned advantages of hydrogen cryo-compression over the traditional compression, it is well known that the energy cost necessary to liquefy hydrogen is a strict 
limitation, being $30 \%$ of the chemical energy stored based on the hydrogen lower heating value (LHV) (138). Another important drawback hindering the use of cryo-compressed vessels, especially in automotive applications, is that they are not yet able to ensure a 10 yearlong vacuum stability. Such a level of vacuum stability can be only achieved by using metal surfaces baked at high temperature, whereas the inner pressure vessel is commonly made of composite materials. One technical solution might be the adoption of custom getters (136). Table 5 gathers the main characteristics of a few representative examples of hydrogen cryogenic compressors.

Table 5 - Main features of hydrogen cryogenic compressors

\begin{tabular}{|c|c|c|c|c|c|}
\hline \multicolumn{6}{|c|}{ CRYOGENIC COMPRESSORS } \\
\hline & $\begin{array}{c}\mathbf{P}_{\text {in }} \\
{[\mathrm{MPa}]}\end{array}$ & $\begin{array}{c}\mathbf{P}_{\text {out }} \\
{[\mathrm{MPa}]}\end{array}$ & $\begin{array}{c}\text { Flow } \\
{\left[\mathrm{Nm}^{3} / \mathrm{h}\right]}\end{array}$ & Application & $\begin{array}{c}\text { Efficiency } \\
{[\%]}\end{array}$ \\
\hline $\begin{array}{c}\text { Kunze et Kircher } \\
(\mathbf{1 4 8 )}\end{array}$ & no data & 30 & $>1000$ & $\begin{array}{l}\text { - Hydrogen refuelling } \\
\text { station }\end{array}$ & no data \\
\hline Linde (127) & no data & $35-90$ & $>1000$ & $\begin{array}{l}\text { - Hydrogen refuelling } \\
\text { station } \\
\text { - Fuel cells vehicles }\end{array}$ & no data \\
\hline Advantages & \multicolumn{5}{|c|}{$\begin{array}{l}\text { - High hydrogen density } \\
\text { - High volumetric efficiency } \\
\text { - High gravimetric and volumetric capacities }\end{array}$} \\
\hline Disadvantages & \multicolumn{5}{|c|}{$\begin{array}{l}\text { - Low temperatures } \\
\text { - Difficulty in managing thermal insulation } \\
\text { - Energy cost for liquefaction } \\
\text { - Vacuum stability }\end{array}$} \\
\hline
\end{tabular}

\subsection{Metal hydride compressors}

Metal hydride compressors ensure an efficient hydrogen compression without any moving part, whether using solid or liquid pistons, or diaphragms. They are also well-known as "thermally powered" compressors, since they are based on the properties of hydride-forming metals, alloys or intermetallic compounds, to absorb and desorb hydrogen simply by means of heat and mass transfer in the reaction system (149). This technology is specific to hydrogen applications: in fact, it was first demonstrated in the 1970s as a hydrogen refrigerator (150) and as an innovative method for storing hydrogen. During the last years, it has been used for 
different hydrogen applications like compression, storage, cryogenics and actuators (151). Several studies focused on the use of metal hydrides for hydrogen compression, and were thoroughly reviewed elsewhere (152).

A metal hydride is a binary combination of hydrogen and a metal (elemental metal, alloy or intermetallic compound) in which the latter reacts reversibly with hydrogen (59):

$$
M_{s}+\frac{x}{2} H_{2(g)} \underset{\text { desorption }}{\stackrel{\text { absorption }}{\rightleftarrows}} M H_{x(s)}+Q
$$

Hydrogen absorption is an exothermic process, accompanied by the release of heat $(Q$ in Eq. (2)), while desorption is endothermic so that hydrogen is released only upon supply of heat. A metal hydride hydrogen compressor essentially consists of a stainless steel tank containing the metal hydride and a heat source/sink (Fig. 10). Different tank designs were developed, and were reviewed in-depth elsewhere (153). The tubular configuration is largely adopted as it facilitates mass and heat exchanges. It consists in a narrow central artery, aimed to distribute hydrogen inside the reactor, and an annular space between the artery and the tank wall where the metal hydride is packed. When low-pressure hydrogen is introduced into the metal hydride tank through the central artery, it is spread in the metal hydride bed and hydrogen exothermic absorption occurs. Absorption starts at low temperature, and continues until the equilibrium pressure is equal to the supply pressure. In order to evaluate the equilibrium pressure at which both metal-hydrogen solution and hydride phase coexist, the Pressure-composition (P-c) isotherms, specific to a given hydride-forming material, are used (154). Once the equilibrium pressure is reached, hydrogen desorption can be carried out by supplying heat to decompose the metal hydride. Desorption produces the increase of the hydrogen pressure to the desired discharge pressure, and allows reaching a new P-c equilibrium. In brief, hydrogen compression is the result of sequential cooling and heating of the metal hydride structure at it is controlled almost entirely by heat transfer (155). Natural air 
convection or forced air are generally used to manage the heat transfer inside the reactor, but an extensive number of applications are also based on water- or oil-cooling systems (152). Heat exchange can be driven through the external surface of the wall; the outer diameter of the tubular reactor is generally not larger than $30 \mathrm{~mm}$ in order to allow an efficient heat transfer in the radial direction (153). Correspondingly, a height to diameter ratio larger than 10 is used to hold a satisfying amount of metal hydride. Thus, it is possible to realise a thermally-driven compression with a very simple design and operation, without moving parts as well as without problems related to wear, noise or intensity of energy used. Moreover, it is not necessary to use large volumes, resulting in compactness and an easier integration within infrastructures and hydrogen plants (156). With a high-temperature heat source, the achievable discharge pressure can be 3 to 10 times the supplied one (157) with volumetric efficiencies up to $93 \%$ (158). Nevertheless, with such compressors, known as single-stage metal hydride compressors, the discharge pressure achievable by using moderate temperatures is not very high $(159,160)$.

Hydrogen users, such as ammonia producers or some laboratory practices, as well as the innovative hydrogen refuelling plants, require hydrogen at $70 \mathrm{MPa}$ (161). Several studies $(162,163)$ showed that such a goal is achievable by using a multistage hydride compressor, in which a series of coupled modules containing metal alloys with different equilibrium hydrogen pressures at the same temperature promotes the cyclical absorption and desorption of hydrogen under specific thermodynamic conditions, allowing a progressive increase of the outlet pressure (156). The development of such compressors requires a trade-off between the pressure level and the overall efficiency to be reached (157). 
THERMAL

SOURCE DISCHARGE

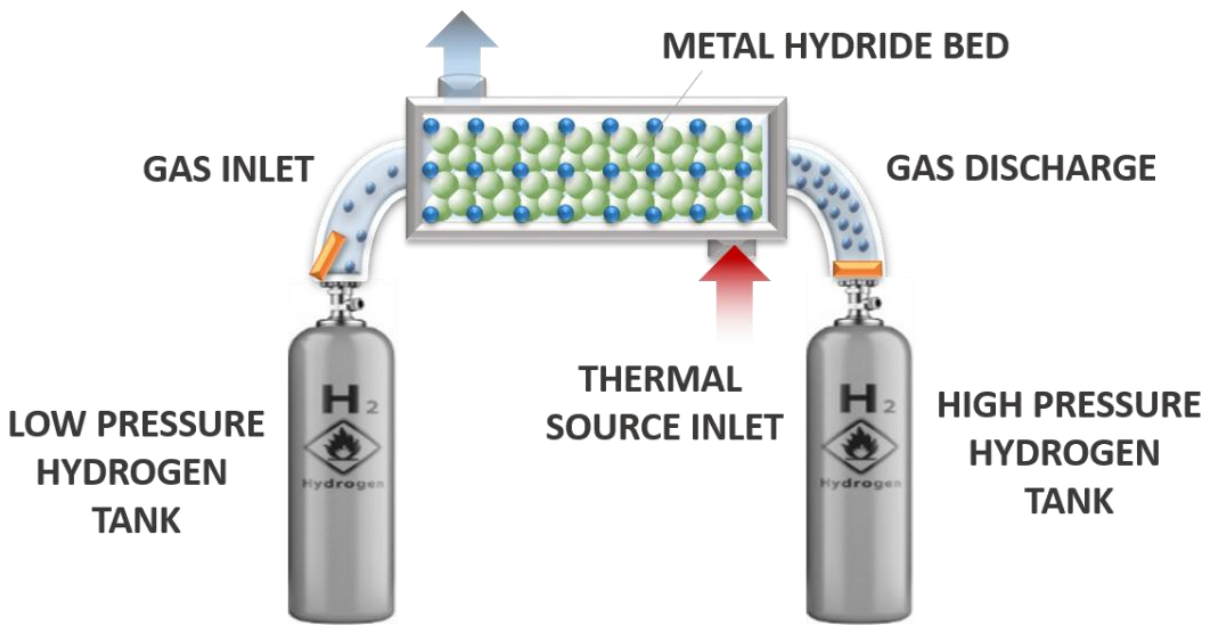

Fig. 10 - Scheme of a single-stage metal hydride hydrogen compressor

The selection of well-suited hydride alloys (Fig. 11) is fundamental in order to have an efficient hydrogen compression. Several requirements have to be satisfied, like high disassociation pressures at moderate temperatures, high hydrogen storage capacity, fast kinetics, easy activation (i.e., treatments to optimise sorption capacities and kinetics in order to obtain good charge-discharge cyclability), and low costs $(160,164)$. The Ni-based $\mathrm{AB}_{5}$ hydrides have proven to be an appropriate option, as they are not very expensive and exhibit good performances, especially at moderate temperatures. $\mathrm{LaNi}_{5}(150)$ was the first Ni-based $\mathrm{AB}_{5}$ alloy used for hydrogen compression; when nickel was partially substituted by aluminium, the storage capacity increased (163). Although it is really difficult to achieve pressures higher than $10 \mathrm{MPa}$ by using only a single-stage hydride compressor (165), it is possible to achieve $70 \mathrm{MPa}$ by adopting a double-stage configuration (163). Ti-based $\mathrm{AB}_{2}$ hydrides are also widely used for hydrogen compression, being able to achieve $70 \mathrm{MPa}$ through a multistage configuration (162), ensuring higher compression factors and good storage properties (157), even though they require extremely low temperatures to operate (166). Vanadium-based BCC solid solution alloys have also shown promising hydrogen 
absorption capacities with fast absorption / desorption kinetics at ambient temperature: Ti-V based alloys reached $65 \mathrm{MPa}$ at moderate temperature when small amounts of niobium and manganese were added in the alloy structure (167)(168). Finally, AB-type intermetallic compounds, especially TiFe-based alloys, exhibit advantages over the $\mathrm{AB}_{5}$ materials in terms of hydrogen storage capacity, low cost and abundance of raw materials for manufacturing them, but they are affected by poor activation behaviour, thus requiring specific thermal treatments in order to reach high discharge pressures (169).

\begin{tabular}{|l|l|l|}
\hline Group & Structure of alloy & Structure of hydride \\
\hline BCC & & \\
\hline & & \\
\hline TiFe & & \\
\hline
\end{tabular}

Fig. 11 - Crystal structure of alloys and corresponding hydrides used for metal hydride hydrogen compressors (reprinted from (152) with permission from Elsevier).

The real advantage of metal hydride compressors is that the energy feeding the system can derive from waste industrial heat instead of electricity (170), or be of renewable origin, mainly solar (171). These features can significantly decrease the system (or OPEX) costs with 
respect to those of mechanical compressors, considering that electricity is certainly more expensive (60). High-pressure hydrogen can be obtained in situ from water by connecting metal hydride compressors to the outlet of an electrolyser, recovering in this way the electrolyser heat losses (172). In reality, high-pressure electrolysis is not feasible because hydrogen can cross the membrane of the electrochemical cell, reacting with oxygen and decreasing the performances of the system (173). For this reason, the maximum operating pressure of an electrolyser is $13.8 \mathrm{MPa}$, and the use of a compact metal hydride compressor downstream of an electrolyser can be a valid solution to reach higher pressures. Hydrogen refuelling stations is another interesting application of metal hydride hydrogen compressors, strengthened by the rapid development of fuel cell vehicles during the last years. The latter application is feasible due to their high volumetric storage capacity, environment-friendliness, and a larger compactness compared to other typologies of compressors. Thus, a hydrogen metal hydride compressor was integrated in a hydrogen refuelling station of fuel cell-powered forklifts by the HySA Systems Competence Centre in South Africa (174). Finally, metal hydride hydrogen compressors can represent a great advantage for industrial customers producing low-pressure hydrogen, as they can obtain high-pressure hydrogen by connecting their pipelines to a compact thermally-driven compressor (175).

The efficiency of a hydrogen metal hydride compressor is generally below $25 \%$ at $423 \mathrm{~K}$ (152) and strictly depends on the compression rate and on the amount of heat provided to the system; it can be defined as the ratio of compression work to heat input. The energy losses related to heat transfer, the heat supplied to the system for hydrogen desorption, and the energy related to cooling must be considered in the evaluation of the efficiency. For instance, if a heat pump is used for cooling, the overall energy consumed in the compression process increases, hence a resultant decrease of efficiency. An efficiency of $7.3 \%$ was calculated for a hydrogen metal hydride compressor with a pressure ratio of 8.76 and a desorption temperature 
of $368 \mathrm{~K}$ (158). On average, the efficiency of a hydrogen metal hydride compressor does not exceed 10\%, as shown in Table 6. Using heat recovered from an electrolyser or higher desorption temperatures could improve the compression efficiency (176). The efficiency of hydrogen metal hydride-based compressors are particularly affected by the limited heat transfer between the heating/cooling fluid and the metal hydride alloy (177). This is due to the low thermal conductivity of the metal hydride bed, offering good performances only when its value is increased up to around $6 \mathrm{~W} / \mathrm{m} / \mathrm{K}$ (164). A copper coating of approximately $1-2 \mu \mathrm{m}$ could be applied at the surface of the metal hydride powder in order to improve the thermal conductivity (178). The system efficiency can be also affected by impurities like oxygen, carbon monoxide, sulphur dioxide, methane and nitrogen in the feeding gas, decreasing both the hydrogen capacity upon cycling and the absorption kinetics (179).

The design parameters of the reactors, such as thickness, dimension and combination with the cooling system, can be optimised in order to achieve good performances of a metal hydride compressor. In particular, the bed thickness and the void fraction in the metal hydride bed are important parameters to take carefully into account in the design of thermally-driven compressors. In fact, during the absorption process, an expansion of the solid bed occurs when hydrogen penetrates inside the metal hydride. Therefore, continuous absorption and desorption cycles may pulverise the alloys into small particles, because of the repeated expansion and contraction of the material's volume. If an irreversible deformation occurs, the hydrogen capacity of the hydride may be significantly hindered, with a resultant decrease of the overall efficiency (162). Moreover, it is important to guarantee a high hydrogen filling of the structure, in order to avoid the presence of empty space, being detrimental for the productivity. Nevertheless too high filling densities, exceeding $61 \%$ of the material density in the hydrogenated state, can lead to structural deformation or even to the damage of the hydride container (180). The common way of mitigating this negative effect on the metal 
hydride compressor is to impose a large length to diameter ratio, or to place the container horizontally. It was also proved that a layer of oxides usually covers the surface of the hydride as a result of an improper process of preparation of the alloys (181). The current efforts for optimising the design as well as the manufacturing technology might result in a significant price decrease (152). Table 6 gathers the main characteristics of a few representative examples of metal hydride hydrogen compressors.

Table 6 - Metal hydride hydrogen compressors

\begin{tabular}{|c|c|c|c|c|c|}
\hline \multicolumn{6}{|c|}{ METAL HYDRIDE COMPRESSORS } \\
\hline & $\begin{array}{c}\mathbf{P}_{\text {in }} \\
{[\mathrm{MPa}]}\end{array}$ & $\begin{array}{c}\mathbf{P}_{\text {out }} \\
{[\mathrm{MPa}]}\end{array}$ & $\begin{array}{c}\text { Flow } \\
{\left[\mathrm{Nm}^{3} / \mathbf{h}\right]}\end{array}$ & Application & $\begin{array}{c}\text { Efficiency } \\
{[\%]}\end{array}$ \\
\hline Madaria et al. (171) & 1 & 3.5 & no data & no data & 6.07 \\
\hline \multirow[b]{2}{*}{$\begin{array}{l}\text { Shmal'ko Y.F. et al. } \\
(182,183)\end{array}$} & 0.3 & 15 & 10 & $\begin{array}{l}\text { - Argon purification for Lviv } \\
\text { Chemical Plant }\end{array}$ & 4.48 \\
\hline & 1.5 & $\begin{array}{c}400 \\
\text { (cryogenic) }\end{array}$ & 0.24 & $\begin{array}{l}\text { - Synthesis of metal hydrides, } \\
\text { deuterides and tritides } \\
\text { - Modification of plastic and } \\
\text { magnetic properties of metals }\end{array}$ & 2.44 \\
\hline Da Silva E.P. (184) & 1 & 10 & 0.42 & $\begin{array}{l}\text { - Compression of high-purity } \\
\text { hydrogen }\end{array}$ & $4-7$ \\
\hline Solovey et al. (161) & 1 & $15-30$ & $0.7-1.4$ & - Ammonia production & $0.92-3.9$ \\
\hline Bhuiya et al. (185) & $1.3-4$ & $10-15$ & no data & $\begin{array}{l}\text { - Efficient hydrogen storage at } \\
\text { room temperature }\end{array}$ & no data \\
\hline $\begin{array}{l}\text { Lototskyy et al. } \\
\text { (186) }\end{array}$ & 1 & 20 & 1 & - Industrial applications & 1.65 \\
\hline \multirow[b]{2}{*}{ Yartys et al. (175) } & 1 & 20 & 10 & $\begin{array}{l}\text { - HyNor Lillestrom refuelling } \\
\text { station (Oslo) }\end{array}$ & no data \\
\hline & 0.3 & 20 & 5 & $\begin{array}{l}\text { - Industrial applications } \\
\text { (Eskom Holdings Ltd. South } \\
\text { Africa) }\end{array}$ & no data \\
\hline \multirow{2}{*}{ Hu et al. (187) } & 2 & 35 & 0.19 & - Fuel cells vehicles & no data \\
\hline & 2 & 38 & 0.28 & - Fuel cells vehicles & no data \\
\hline Kelly et al. (173) & 14 & 41 & no data & $\begin{array}{l}\text { - Hydrogen refuelling station } \\
\text { and Fuel Cells vehicles }\end{array}$ & $3-5$ \\
\hline Wang et al. (159) & 4 & 45 & $1.2-2.4$ & - Fuel cells on-board storage & no data \\
\hline Wang et al. (162) & 4 & 70 & no data & - Hydrogen refuelling station & no data \\
\hline Li et al. (163) & 5 & 70 & 2 & $\begin{array}{l}\text { - Lightweight hydrogen } \\
\text { storage vessel }\end{array}$ & no data \\
\hline $\begin{array}{l}\text { Pickering et al. } \\
\text { (167) }\end{array}$ & no data & 65 & no data & - Automotive applications & no data \\
\hline Advantages & \multicolumn{3}{|c|}{$\begin{array}{l}\text { - Thermally-driven compression } \\
\text { - Absence of moving parts } \\
\text { - Compact design }\end{array}$} & \multicolumn{2}{|c|}{$\begin{array}{l}\text { - Safety } \\
\text { - Absence of noise } \\
\text { - High-purity hydrogen }\end{array}$} \\
\hline Disadvantages & \multicolumn{3}{|c|}{$\begin{array}{l}\text { - Limited heat transfer } \\
\text { - Necessity of using appropriate alloys } \\
\text { - Low efficiency }\end{array}$} & \multicolumn{2}{|c|}{$\begin{array}{l}\text { - Weight } \\
\text { - Cost of container/ compression elements }\end{array}$} \\
\hline
\end{tabular}

\subsection{Electrochemical compressors}


An electrochemical hydrogen compressor, also known as "electrochemical hydrogen pump", is an innovative device that can be used to compress hydrogen with high recovery ratios, up to $95 \%$ (188), and in applications requiring low gas quantities at very high pressures. It is based on the same basic principles as those of a proton-exchange membrane fuel cell (PEMFC). Low-pressure hydrogen $\left(p_{a}\right)$ is fed to the anode of an electrochemical cell, where it splits into protons and electrons, according to the reaction:

$$
H_{2} \rightarrow 2 H^{+}+2 e^{-}
$$

Protons flow electrochemically through a solid polymer electrolyte, whereas electrons follow an external path, which is the electrical circuit controlled by the potential differential supplied to the system. Once protons and electrons reach the cathode, they recombine to form hydrogen molecules again, with a resultant increased pressure, $p_{c}$ (Fig. 12):

$$
2 H^{+}+2 e^{-} \rightarrow H_{2}
$$

This process continues as long as the driving force provided by the current, i.e., the electric energy supplied to the system, exceeds the internal energy of the system itself (189). The oxidation rate at the anode, i.e., the rate at which low-pressure hydrogen is converted into protons, can be evaluated from Faraday's law (190):

$$
\frac{d n}{d t}=\frac{I}{2 F}
$$

where $n$ is the inlet hydrogen flow in [mol], $F=9.648 \times 10^{4} \mathrm{C} / \mathrm{mol}$ is the Faraday constant and $I$ is the current [A]. Eq. 5 clearly shows that the higher is the current supplied, the higher is the rate at which protons are transferred from the anode to the cathode. 


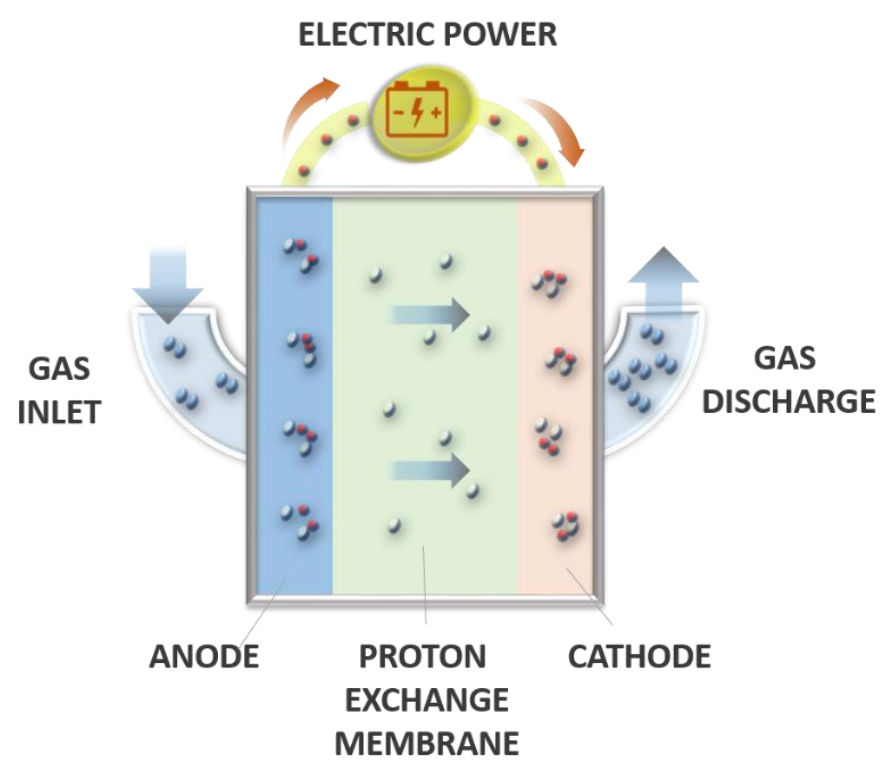

Fig. 12 - Scheme of an electrochemical compressor

The performance of an electrochemical compressor is governed by the Nernst equation, which gives the relationship between the achievable pressure ratio and the voltage supplied to the system:

$$
E_{\text {nernst }}=E_{0}+\frac{R T}{2 F} \ln \frac{p_{c}}{p_{a}}
$$

where $E_{0}$ is the cell potential at standard conditions (considered 0 in the case of an electrochemical compression), $R$ is the universal gas constant, $T$ is the absolute temperature, and $F$ is the charge of 1 mole of electrons. The discharge pressure strictly depends on the electrical voltage supplied to the system: the higher the latter, the higher the pressure at which protons are reduced at the cathode. In other words, the Nernst potential indicates the minimum amount of voltage to apply to the system for achieving the desired compression ratio. According to the Nernst equation, a potential differential of only $0.054 \mathrm{~V}$ is enough to increase the hydrogen pressure from 1 to $70 \mathrm{MPa}$ at room temperature (191). Nevertheless, an electrochemical compressor is affected by several voltage losses, thus a higher voltage than 
the Nernst potential must be supplied to the system in order to reach the desired discharge pressure. These voltage losses are the activation overpotentials and the Ohmic losses (188), as shown in Eq. 7:

$$
E=E_{0}+\frac{R T}{2 F} \ln \frac{p_{c}}{p_{a}}+\eta_{a}+\eta_{c}+r I
$$

$\eta_{a}$ and $\eta_{c}$ are the anode and cathode overpotentials, which can be defined as the potential losses due to the reactions kinetics (192). Actually, both hydrogen oxidation and reduction reactions are highly reversible in an electrochemical compressor, thus the overpotential contribution to the cell voltage can be considered as negligible (188). Finally, the last term of Eq. (7) is clearly related to the Ohmic losses, and the term $r$ incorporates the electrical resistances of membrane, electrode and cell hardware. Actually, the electrical resistance of the membrane is the main factor affecting the performance of a hydrogen electrochemical compressor (193), and it is strictly related to the proton conductivity of the polymer electrolyte membrane. Thus, in order to decrease the Ohmic losses, a high ionic conductivity of the membrane is required (194). High mechanical and chemical stabilities, as well as resistance to high temperature are other crucial features.

The membrane currently used in hydrogen electrochemical compressors is based on perfluorocarbon sulfonate polymers, e.g. Nafion ${ }^{\circledR} 117(132,188)$, which allows the selective transfer of one or few cationic species, protons in the case of a hydrogen electrochemical compressor. In order to ensure optimum compression performances, a good hydration level of the membrane is required, since its protonic conductivity is enhanced while the membrane is saturated with water. Hence, protons cross the membrane in the hydrated form $\mathrm{H}_{2 n+1} \mathrm{O}_{n}^{+}$, where $n$ is the electro-osmosis coefficient. This strict requirement highlights the importance of an efficient water management inside the system. In fact, unlike in proton-exchange membrane fuel cells, water is not a reaction product in an electrochemical compressor, so it is 
necessary to develop a control system monitoring the humidity level on both sides of the cell, e.g. by addition of water to the anode compartment, thus preserving the optimal hydration degree of the membrane (195). Besides, the use of Nafion ${ }^{\circledR}$ as proton-exchange electrolyte in an electrochemical compressor, as well as in other PEM devices, implies operation at low temperatures, typically below $353 \mathrm{~K}$ (196), since higher temperatures can affect the stability of the perfluoro-sulfonate polymer. Nafion is also quite expensive (197), and difficult to dispose because of its intrinsic acidic nature, thus requiring specific post-treatments (198). For these reasons, several alternative materials were investigated in order to substitute Nafion®. A sulphonated poly(ether ether ketone)/crosslinked poly(styrene sulphonic acid) SPEEK/CrPSSA semi-interpenetrating polymer network membrane was investigated (199). Such a membrane exhibited very high proton conductivity and was cheaper than Nafion® membranes. However, the energy efficiency was lower than that commonly obtained with Nafion ${ }^{\circledR}$. Hydrogen-sulphated fullerenol was also tested in a system consisting of a first electrochemical stage followed by a $\mathrm{LaNi}_{5}$ metal hydride compressor reaching hydrogen pressures up to $1 \mathrm{MPa}(200)$.

Both reactions (3) and (4), i.e., the hydrogen oxidation at the anode and its reduction at the cathode, respectively, are catalytically-driven processes, and take place on the "three-phase boundary" points (194) where the electric circuit, the membrane and the gas phase are in intimate contact. Since the rate of the single electrochemical reactions can significantly affect the performance and the efficiency of electrochemical compressors, the membrane, the electrodes and the catalyst can be assembled in membrane electrode assembly (MEA) to speed up the electrochemical process, in which metal nanoparticles are dispersed in a solid electrolyte matrix. Noble metals, especially platinum, platinum-ruthenium and palladium are selected (194) because of their excellent catalytic properties. The proton-exchange membrane (PEM) technology adopts MEAs consisting in $0.1-0.2 \mathrm{mg} / \mathrm{cm}^{2}$ platinum-based catalyst 
dispersed on a Nafion ${ }^{\circledR} 117$ membrane (132). Unfortunately, the use of noble metals onto the electrodes induces a high poisoning risk by $\mathrm{CO}$ (201), thus the gas flow fed to the cell must be as free of $\mathrm{CO}$ as possible. The MEA is "sandwiched" between two current collectors; rigid porous titanium can be used on the anode side to withstand the pressure gradient, whereas porous carbon papers can be employed on the cathode side. Both current collectors are pressed on the two sides of the MEA, forming a single electrochemical cell. Finally, the optimal design of an electrochemical compressor includes also extremity channels to evenly distribute hydrogen inside the cell, whose shape does not affect the overall efficiency of the system. Indeed, the hydrogen diffusion rate in the gas phase is larger than the protons transport rate through the electrolyte, which actually represents the main operating issue of all electrochemical devices (195).

A proper design of an electrochemical cell allows a service life higher than 20000 hours (202) and the achievement of high-pressure hydrogen storage, typically between 20 to 35 MPa. Grigoriev et al. (203) showed that it is possible to compress hydrogen from atmospheric pressure to almost $5 \mathrm{MPa}$ in a single electrochemical step by applying a cell voltage of 140 $\mathrm{mV}$ and a current density of $0.2 \mathrm{~A} / \mathrm{cm}^{2}$, with a corresponding energy consumption of around $0.3 \mathrm{kWh} / \mathrm{Nm}^{3}$. Current densities in the range $0.1-1 \mathrm{~A} / \mathrm{cm}^{2}$ are commonly used in electrochemical devices. High current densities can be beneficial in terms of investment cost, but detrimental in terms of energy consumption. The opposite applies for lower current densities.

Besides, even if very high discharge pressures could be achieved by properly designing an electrochemical cell, this is not convenient from practical and economical points of view. First of all, the Nernst potential becomes of the same order of magnitude than the Ohmic losses at very high pressure, resulting in an overall reduced efficiency (204). Additionally, high pressure differences between the electrodes increase the hydrogen permeation from the 
cathode side to anode side, thus decreasing the compression efficiency. The hydrogen permeation rate across the membrane can be calculated as follows (205):

$$
\dot{m}=-\mathcal{D} A \frac{\Delta P}{d}
$$

where $D$ is the diffusion coefficient, $A$ the membrane cross-section area, $d$ the thickness of the membrane and $\Delta P$ the differential pressure between the two electrodes. Thus, a large pressure difference between the cathode and the anode causes dissolved molecular hydrogen to cross the membrane by diffusion because of the gas concentration gradient between the two electrodes. Moreover, some calculations showed that hydrogen permeation can be reduced by decreasing the cell temperature (132). Hydrogen permeation should be minimised to ensure a good Faradaic efficiency, defined as:

$$
\eta_{f}=\frac{I-I_{\text {loss }}}{I}
$$

where $I$ is the effective current density of the electrochemical compressor and $I_{\text {loss }}$ is the detrimental contribution to the current due to hydrogen permeation. A thicker membrane can reduce hydrogen permeation; however, it can increase in turn the Ohmic losses, as the membrane electric resistance is proportional to the membrane dimensions. At high pressure, a stronger structure is also required for avoiding MEA deformation. Hence, reinforced endplates can be added to both anode and cathode to hold together the elements constituting the assembly. All the aforementioned drawbacks related to high-pressure applications in single electrochemical compressors limit the achievable discharge pressure: in fact, the highest value reached was only 16.8 $\mathrm{MPa}$ (205). In order to reach the pressure level required for many hydrogen applications (161), a cascade of multiple single cells can be adopted. It was proved that, with a multi-stack configuration, very high pressures up to $85.7 \mathrm{MPa}$ can be reached (206). The company HyET has also demonstrated that it is possible to reach $100 \mathrm{MPa}$ with the same operating principles (207). Moreover, in applications in which small hydrogen flowrates 
are required, an efficiency equal to $90 \%$ is potentially achievable (208), with low voltages and current densities up to $1 \mathrm{~A} / \mathrm{cm}^{2}$ (189). The multi-stack solution seems to be more advantageous than a multistage mechanical compressor: an electrochemical device is able to reach the same pressure level as a mechanical one by relying on a fewer number of stages, with no noise produced and a simpler design (209). Moreover, electrochemical compressors show a higher efficiency than mechanical compressors. Whereas $7 \mathrm{kWh} / \mathrm{kg}$ are necessary to compress hydrogen up to $20 \mathrm{MPa}$ by using a mechanical compressor, only $2 \mathrm{kWh} / \mathrm{kg}$ are needed in the case of the electrochemical compressor (67). Special care must be taken when comparing data from different studies, because they consider different definitions of efficiency. Electrochemical compression efficiency is defined as follows:

$$
\eta_{c}=\frac{E_{n e r n s t}-\Delta E}{E_{n e r n s t}}
$$

where $E_{\text {nernst }}$ is the Nernst voltage according to Eq. 6 and $\Delta E$ is the increase between pressurised and ambient pressure operation. When the electrochemical compression efficiency is combined to the Faradaic efficiency, the total electrochemical compression efficiency is obtained. The latter can be as high as $95 \%$ at low pressure, up to $1 \mathrm{MPa}$ (210), since the electrochemical compression is isothermal at low pressure. On the other hand, high pressure conditions are not beneficial in terms of efficiency, because of the increase of the hydrogen permeation across the membrane with the resulting decrease of the Faradaic contribution. Besides, by taking into account the deviation of the effective cell voltage from the Nernst voltage according to Eq. 7, an overall cell efficiency can be considered:

$$
\eta_{\text {cell }}=\frac{E_{\text {nernst }}}{E} \frac{I-I_{\text {loss }}}{I}
$$

According to this definition, efficiencies around $60 \%$ were obtained at low pressure $(<10$ $\mathrm{MPa}$ ) and with an operating current density of around $1 \mathrm{~A} / \mathrm{cm}^{2}$. Even if the cell efficiency is lower than the electrochemical compression efficiency, the hydrogen electrochemical 
compressor can be considered as highly efficient in comparison to the mechanical compressors.

As mentioned above, hydrogen electrochemical compressors exhibit a high efficiency when the discharge pressure is moderate; hence, even if several studies showed that such a system is potentially able to reach pressures up to $100 \mathrm{MPa}$ (207), it is not convenient from practical and energetic points of view. The use of hydrogen electrochemical compressors was shown to be a good and efficient solution when combined to other compressor systems, such as metal hydride compressors (190) or mechanical compressors, as foreseen by the PHAEDRUS project aimed to realise a commercial hydrogen refuelling station featuring a hybrid hydrogen compression system (207). Furthermore, as electrochemical compressors require also lower energy consumption at lower pressure range, they can be used at the outlet of an electrolyser in order to produce hydrogen at very high pressure with an enhanced efficiency of the whole system. Hydrogen electrochemical pumps could be also used for recirculating hydrogen in a fuel cell system: the recirculation of hydrogen on the anode side of a fuel cell can allow decreasing the voltage fluctuation and the number of purging operations, resulting in a higher fuel cell efficiency than in the case of dead-ended mode (204). Besides, it is worth highlighting that one the most important advantages of an electrochemical compressor is that it ensures vibration-free operation with no moving parts. This feature makes them ideal for the development of cryocoolers for infrared detectors in aerospace applications, since the mechanical compressors commonly used produce significant vibration on the spacecraft, causing substantial image artefacts (202). Finally, if hydrogen is mixed with other gas, e.g. nitrogen or carbon dioxide, the hydrogen compressor is able to work even as a purifying device, producing high-purity hydrogen flows (211). Table 7 gathers the main characteristics of a few representative examples of hydrogen electrochemical compressors. 
Table 7 - Hydrogen electrochemical compressors

\begin{tabular}{|c|c|c|c|c|c|}
\hline \multicolumn{6}{|c|}{ ELECTROCHEMICAL COMPRESSORS } \\
\hline & $\begin{array}{c}\mathbf{P}_{\text {in }} \\
{[\mathrm{MPa}]}\end{array}$ & $\begin{array}{c}\mathbf{P}_{\text {out }} \\
{[\mathrm{MPa}]}\end{array}$ & $\begin{array}{c}\text { Flow } \\
{\left[\mathrm{Nm}^{3} / \mathrm{h}\right]}\end{array}$ & Application & $\begin{array}{c}\text { Efficiency } \\
{[\%]}\end{array}$ \\
\hline Rohland et al. (132) & 0.1 & 4.3 & $0.04-5.7$ & - Low power application & no data \\
\hline Strobel et al. (188) & 0.1 & $4.3-5.4$ & $1-6$ & - Electrolysers & 80 \\
\hline $\begin{array}{c}\text { Grigoriev et al. } \\
(\mathbf{2 0 3})\end{array}$ & no data & 13 & 0.01 & $\begin{array}{l}\text { - Hydrogen separation from gas } \\
\text { mixtures }\end{array}$ & no data \\
\hline HyEt (191) & 0.1 & $70-100$ & 1 & $\begin{array}{l}\text { - Hydrogen refuelling } \\
\text { - Hydrogen purification } \\
\text { - Hydrogen recycling } \\
\text { - Energy storage }\end{array}$ & no data \\
\hline Wong et al. (206) & 0.1 & 85.7 & no data & $\begin{array}{l}\text { - Hydrogen purification } \\
\text { - Fuel cells industry }\end{array}$ & no data \\
\hline Lipp (208) & $0.1-14$ & $\sim 83$ & 0.06 & no data & $95^{*}$ \\
\hline Moton et al. (209) & 0.35 & $7-100$ & $116-467$ & $\begin{array}{l}\text { - Design for manufacturing } \\
\text { methods (DFMA) cost analysis }\end{array}$ & no data \\
\hline $\begin{array}{l}\text { PHAEDRUS } \\
\text { project }(207)\end{array}$ & no data & 100 & 0.93 & $\begin{array}{l}\text { - Refuelling hydrogen station } \\
\text { - Energy storage }\end{array}$ & no data \\
\hline $\begin{array}{l}\text { DON QUICHOTE } \\
\text { project }(207)\end{array}$ & no data & 40 & 28 & $\begin{array}{l}\text { - Energy storage with wind / } \\
\text { solar energy }\end{array}$ & no data \\
\hline Advantages & $\begin{array}{l}\text { - Low co } \\
\text { - Produc } \\
\text { - No mo } \\
\text { - Very hi } \\
\text { - Use as }\end{array}$ & $\begin{array}{l}\text { peration } \\
\text { of high-p } \\
\text { parts } \\
\text { compressi } \\
\text { rogen pur }\end{array}$ & $\begin{array}{l}\text { y hydrogen } \\
\text { fficiency }\end{array}$ & & \\
\hline Disadvantages & $\begin{array}{l}\text { - Difficu } \\
\text { - Difficu } \\
\text { - High ce } \\
\text { - Hydrog }\end{array}$ & $\begin{array}{l}n \text { manufa } \\
n \text { realisin } \\
\text { esistance } \\
\text { back diffu }\end{array}$ & $\begin{array}{l}\text { ing the cell } \\
\text { perfect seal }\end{array}$ & issembly & \\
\hline
\end{tabular}

\subsection{Adsorption compressors}

A new emerging technology for hydrogen compression is based on adsorption and proceeds by means of changes in the system temperature, without any mechanical moving unit. A hydrogen adsorption compressor (Fig. 13) can be described as a thermodynamic engine in which compression is controlled by heat transfers between the compression reservoir and the system environment (212). Low-pressure hydrogen is fed to a closed tank filled with a solid bed consisting of a porous material with a high surface area and so a high adsorption potential. At specific temperature and pressure conditions, adsorption takes place exclusively on the surface of the porous material. After adsorption, heat is supplied to the system, resulting in an increase of temperature that produces hydrogen desorption. As a direct 
consequence, the density of the hydrogen bulk phase increases and high-pressure hydrogen is obtained. This is due to the fact that hydrogen moves from the adsorbed phase, which is denser, to the bulk gas phase in a confined tank volume when the temperature increases. Hence, the pressure level potentially achievable strictly depends on the final temperature, on the volume available for the bulk gas phase inside the tank, and on the mass of adsorbent (213).

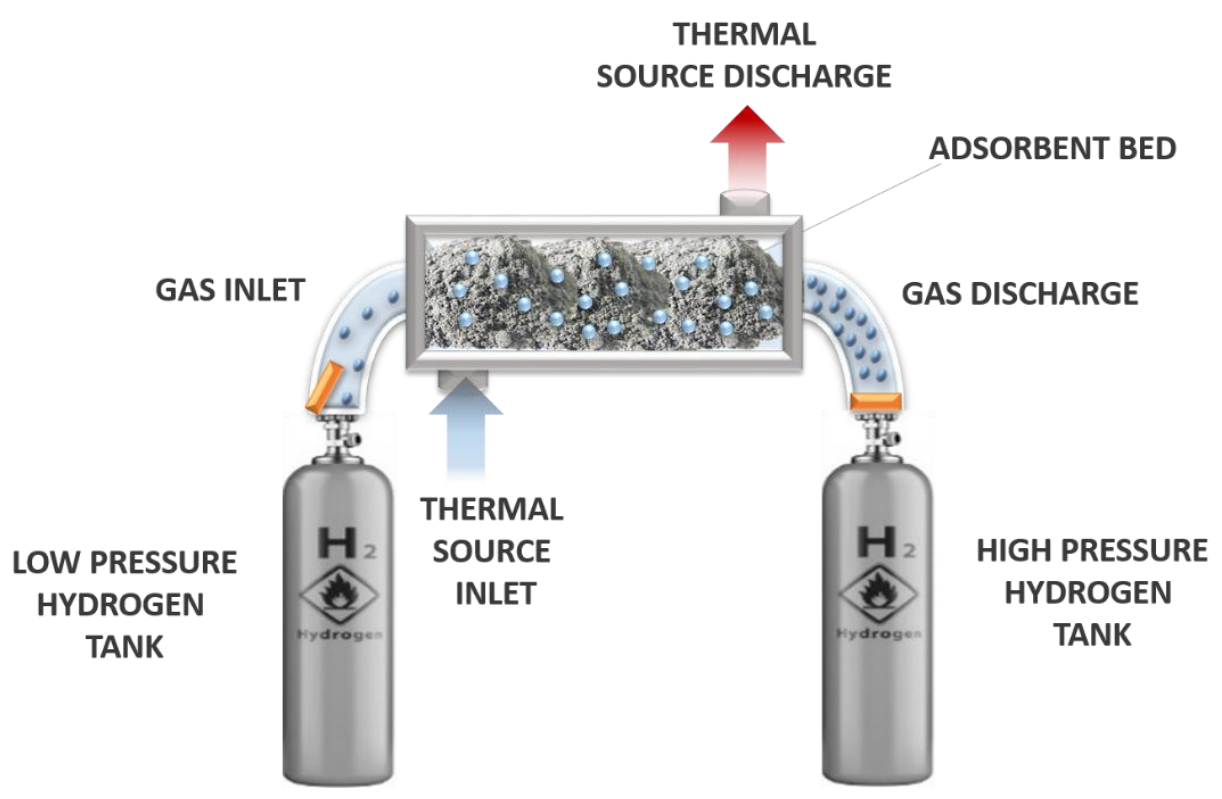

Fig. 13 - Scheme of an adsorption compressor

Important requirements for a well-driven adsorption process are the high surface area and developed porosity of the adsorbent, since the net adsorbed amount of hydrogen strictly depends on the bed total surface area. Several materials have been shown to exhibit enhanced adsorption capacities: carbonaceous materials (i.e., activated carbons, carbon nanotubes or fullerenes), zeolites, and metal organic frameworks (MOFs) (214-216). Adsorption on these materials is a completely reversible process, as it is due to physisorption. The interaction energies involved are very low, of the order of $0.01-0.1 \mathrm{eV}(217)$, meaning that no chemical bonds between hydrogen molecules and the solid bed are generated, so no significant perturbations of the charge distribution occur (218). In fact, hydrogen interacts with the solid bed surface through weak Van der Waals forces, forming a monolayer on the adsorbent 
surface, differently from a chemisorption process in hydrides, which is a volume phenomenon.

Adsorption is an exothermic process and therefore it is enhanced at low temperature. It is possible to evaluate the rate at which hydrogen adsorption occurs by means of the "Linear Driving Force" (LDF) model (219):

$$
\frac{d \bar{C}(t)}{d t}=k_{L}\left[\bar{C}^{*}(t)-\bar{C}(t)\right]
$$

where $\bar{C}(t)$ is the average adsorbate concentration in the adsorbent particle, $\bar{C}^{*}(t)$ is the adsorbed gas in equilibrium with the gas phase at a given temperature and pressure, and $k_{L}$ is the intra-particle mass transfer coefficient. The model assumes that the temperature of the adsorbent particles is constant during the adsorption step, which actually never happens. The rate of adsorption was shown to be quite low in high-temperature conditions. At temperatures close to $298 \mathrm{~K}$, Van der Waals interactions can be of the same order of magnitude as the thermal motion energy of hydrogen molecules on the solid surface. Since the thermal motion energy of hydrogen molecules is proportional to the system temperature (220), the adsorption force can increase only if the system is cooled down. For this reason, hydrogen adsorption is generally driven at temperatures as low as $77 \mathrm{~K}$, i.e., the temperature of liquid nitrogen, easy to achieve from an industrial point of view. This is a strict requirement to compress a satisfying amount of hydrogen: the higher is the amount of hydrogen adsorbed on the porous adsorbent material, the higher is the hydrogen pressure in discharge. Besides, in terms of hydrogen storage capacity, as well as for a safety point of view, several advantages can be obtained at cryogenic temperatures (16).

MOFs are well-known in the context of hydrogen storage: a considerable excess hydrogen adsorption of $9.9 \%$ at $77 \mathrm{~K}$ and $5.6 \mathrm{MPa}$ was measured for a MOF called NU-100, having a 
BET surface area of $6143 \mathrm{~m}^{2} / \mathrm{g}$ and a total pore volume of $2.82 \mathrm{~cm}^{3} / \mathrm{g}$. This value is among the highest ever achieved in the framework of hydrogen adsorption (221). Additionally, carbon materials received large attention as regards to hydrogen applications, due to their highly developed textural properties (high surface areas and pore volumes), moderate cost, and chemical stability (222). Moreover, carbon materials ensure a low-weight system with respect to metal hydrides, thus offering a noteworthy advantage in using an adsorption compressor instead of a metal hydride compressor (223). Experimental works using activated carbon with a BET area of $2630 \mathrm{~m}^{2} / \mathrm{g}$ showed an upper limit for hydrogen storage equal to 6.4 wt.\%, at $77 \mathrm{~K}$ and $4 \mathrm{MPa}$, close to the theoretical limit of 6.8 wt.\% (224). However, hydrogen adsorption capacities up to $1.6 \mathrm{wt} \%$ can be reached at room temperature and $70 \mathrm{MPa}$ by using activated carbons (225), thus highlighting the necessity of low-temperature operations.

Hydrogen adsorption compressors are affected by several thermal effects (226). Firstly, heat is generated during adsorption, whereas heat is needed in order to release hydrogen through desorption (227). Furthermore, the thermal management issues associated with operations at cryogenic conditions can be very detrimental (228), due to the necessity of evacuating the produced heat while maintaining the very low temperatures. During the adsorption / desorption cycles, a large thermal gradient along the adsorbent bed can affect the good operation of an adsorption compressor. A temperature gradient is generated along the reactor primarily because of an inappropriate flow rate upon filling the tank and of a nonefficient heat exchange with the surroundings. If not evacuated, adsorption heat makes the temperature increase, reducing in turn the hydrogen adsorption capacity and the system performances. This feature is enhanced if the tank is filled too fast, since there is not enough time to allow an efficient heat exchange (229), partly due to the low thermal conductivity of the adsorbent bed (230). Hence, the knowledge of temperature and pressure variations during adsorption / desorption stages in an adsorption compressor is essential in order to optimise its 
performance (231). Specifically, it has been proved that in a cylindrical tank the temperature gradient is larger along the radial direction than along the axial one (232). Experimental evidences revealed that the maximum temperature is recorded at the mid-height and on the axis of the adsorbent bed: this position is in fact neither involved in the conductive cooling effect from the walls, nor directly in contact with the fresh hydrogen inlet. Furthermore, the bottom of the tank is hotter than the area close to the walls, being mainly affected by the convective flow coming from the internal hot region of the tank (233). It has even been shown that $78 \%$ of the energy released during the charging process of an adsorption compressor is due especially to the heat generated from the dissipation of the mechanical energy of the feed gas, whereas $22 \%$ derive from the generated adsorption energy (233). For this purpose, precooling the gaseous hydrogen entering the tank, as well as flow-through cooling of the tank, have been proposed (234). Thus, hydrogen at cryogenic temperatures is flown through the adsorptive bed, a part of which is adsorbed, while the rest cools the system (227), ensuring in this way better heat transfers inside the tank. Removing efficiently the adsorption heat is much more difficult: the temperature maximum slightly varies when a water cooling jacket is used for refrigeration (235). In addition, if the stainless steel traditionally used had to be replaced by copper because of its much higher thermal conductivity, thicker walls would be required due to the lower mechanical resistance of copper (235). Thermal management of adsorption compressors can be also done by using liquid nitrogen as refrigerant (236). In that case, the compressor is equipped with internal heat exchangers that are in direct contact with the adsorbent material. Liquid nitrogen flows into them to precool both the adsorbent bed and the hydrogen introduced into the tank. This solution might be economically feasible, taking into account that: (i) activated carbon with high surface areas can be produced at low costs (237); (ii) adsorption compression is totally reversible (218,238-240); and (iii) further 
decreases of capital and operating costs can be obtained because of the cheapness of liquid nitrogen, which is also commonly available (241).

A significant increase of the hydrogen temperature inside a storage tank might be also harmful in terms of safety, since it can affect the mechanical properties of the building materials. For this reason, especially in automotive applications, composite tanks are used (Figure 14): the outer layer, based on carbon fibres, ensures the structural strength of the tank, whereas the inner layer, usually known as "liner", has the important role of leak-tightness, and can be made of metal or plastic. However, in order to obtain a well-driven thermal management of the tank, metal walls should be preferred because of their higher thermal conductivity (242).

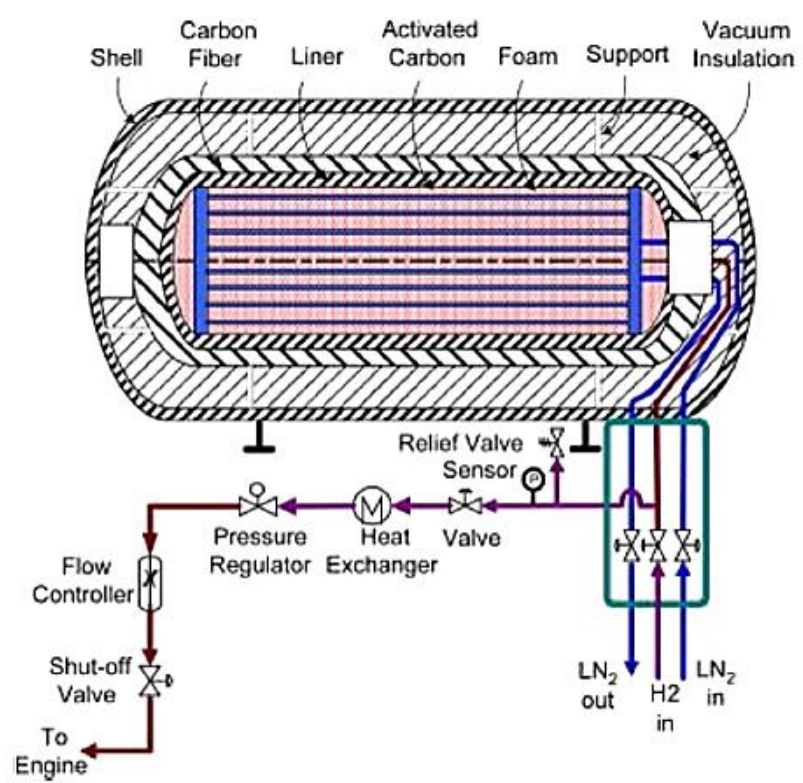

Fig. 14 - Scheme of an adsorption-based tank for hydrogen applications (reprinted from (243) with permission of Elsevier).

An in-depth comparison between hydrogen cryogenic compression and adsorption compression was carried out (135). It was shown that both technologies exhibit advantages, but it is difficult to select one of them as the best solution. On the one hand, adsorption compression offers the advantage of lowering the pressure needed to store a given amount of 
hydrogen, allowing an important benefit in terms of safety. On the other hand, the additional mass due to the presence of adsorbent material can be detrimental for applications in which the weight is crucial, e.g. for the aerospace sector. Moreover, the adsorption compressor is affected by the aforementioned thermal management issues (244).

According to data available in the open literature, hydrogen storage by adsorption at low pressure offers more advantages than mechanical compressed gas, such as: (i) lower costs (245), and (ii) a higher amount of hydrogen stored compared to simple compression in an empty vessel, for low pressures applications and in room temperature conditions, using specific activated carbons (246). Using a compressor based on adsorption on activated carbons instead of pure compression would give a volume gain of around $22 \%$ to the hydrogen storage system (225). Numerical simulations showed that with a reservoir volume of $1 \mathrm{~L}$ and a mass of activated carbon of $0.5 \mathrm{~kg}$, an adsorption compressor can compress hydrogen up to $70 \mathrm{MPa}$ for an inlet pressure of $4 \mathrm{MPa}$ by heating up the system from $77 \mathrm{~K}$ to 298 K. Nevertheless, the efficiency of such a compressor is expected to be low, mainly because of the low thermal conductivity of the adsorbent material. Indeed, the thermal conductivity of the commercial activated carbon NORIT R0.8 is around $0.25 \mathrm{~W} / \mathrm{m} / \mathrm{K}(232)$, in line with values commonly reported for adsorbent packed beds (247). This value can be significantly increased if composite adsorbents, comprising activated carbons and expanded natural graphite, are used. By adopting this solution, a thermal conductivity slightly higher than $2 \mathrm{~W} / \mathrm{m} / \mathrm{K}$ can be achieved (248). Nevertheless, the thermal conductivity of carbon adsorbents is not too far from those measured for metal hydrides, rarely exceeding the value of $1 \mathrm{~W} / \mathrm{m} / \mathrm{K}$ (249). Thus, the efficiency of a hydrogen adsorption compressor, defined as the ratio of compression work to heat input, is expected to be close to that of a metal hydride compressor. 
Hydrogen adsorption compressors seem to be a valid alternative to mechanical compressors for the development of decentralised hydrogen refuelling stations of small and average size. As already investigated in the case of metal hydride compressors (172), an adsorption compressor could be installed downstream of an electrolyser or an electrochemical compressor in order to compress hydrogen in a two-stages process. In fact, the $70 \mathrm{MPa}$ required nowadays for the development of hydrogen refuelling station can be achieved by an adsorption compressor only if the hydrogen inlet pressure is higher than $0.1 \mathrm{MPa}$. Thus, a preliminary compression stage is necessary. Beside the innovative applications involving the automotive use of hydrogen, adsorption compressors have been particularly used in the frame of compressor-driven adsorption cooling systems (250), in which refrigeration is realised through the evaporation of a coolant which was formerly compressed in a thermally-driven device (251). A similar system consists in an adsorptive bed connected to a heat sink and a heat source, so that the heat produced by the gas adsorption is rejected into the heat sink, and the heat of desorption is taken from the heat source. Working in this way, the heat of desorption provides the required cooling. Furthermore, an increase of the compressed gas amount, as well as an enhanced refrigeration, can be obtained using a multiple-bed system (252). Adsorption cryo-coolers are able to ensure good performances at very low temperatures, essential for the operation of infrared detectors and other devices commonly used for aerospace applications. In addition, they do not have any moving part and operations are vibration-free, which are crucial requirements for long-term missions (253). In such devices, the thermal demand required for desorption derives from an electrical energy source (254). A prototype for a high-efficiency adsorption compression, using Saran charcoal as adsorbent material, has been developed by GenCorp-Aerojet (255) in order to operate at 125 K. Table 8 gathers the main characteristics of a few representative examples of hydrogen adsorption compressors. 
Table 8 - Hydrogen adsorption compressors

\begin{tabular}{|c|c|c|c|c|c|}
\hline \multicolumn{6}{|c|}{ ADSORPTION COMPRESSORS } \\
\hline & $\begin{array}{c}\mathbf{P}_{\text {in }} \\
{[\mathrm{MPa}]}\end{array}$ & $\begin{array}{c}\mathbf{P}_{\text {out }} \\
{[\mathrm{MPa}]}\end{array}$ & $\begin{array}{c}\text { Flow } \\
{\left[\mathrm{Nm}^{3} / \mathrm{h}\right]}\end{array}$ & Application & $\begin{array}{c}\text { Efficiency } \\
{[\%]}\end{array}$ \\
\hline $\begin{array}{l}\text { Hermosilla-Lara } \\
\text { et al. (233) }\end{array}$ & 0.1 & 10 & 3.42 & $\begin{array}{l}\text { - Automotive } \\
\text { applications }\end{array}$ & no data \\
\hline Xiao et al. (231) & 0.1 & 10 & 10.08 & no data & no data \\
\hline Tong et al. (234) & no data & 10 & 561 & no data & no data \\
\hline $\begin{array}{c}\text { Richard et al. } \\
(\mathbf{2 4 4 )}\end{array}$ & 0.25 & 35 & 72.6 & no data & no data \\
\hline $\begin{array}{l}\text { Ahluwalia et } \\
\text { Peng (243) }\end{array}$ & 0.8 & 35 & no data & - On board storage & no data \\
\hline Advantages & \multicolumn{5}{|c|}{$\begin{array}{l}\text { - Thermally-driven compression } \\
\text { - No moving parts, no vibration, no noise } \\
\text { - No necessity of sealing } \\
\text { - Low cost of adsorbent }\end{array}$} \\
\hline Disadvantages & \multicolumn{5}{|c|}{$\begin{array}{l}\text { - Low thermal conductivity of adsorbents } \\
\text { - Difficulty in thermal management } \\
\text { - Low-temperature operation }\end{array}$} \\
\hline
\end{tabular}

\section{Cost and efficiency overview of hydrogen compressors}

Selecting the best suitable type of compressor to be implemented in a specific application is not straightforward. Several factors must indeed be taken into account, such as the technology reliability and availability, capital expenditure (CAPEX), operating expenditure (OPEX), efficiency, size, weight, delivery and others. The US Department of Energy (DOE) identified targets to achieve by 2020 in order to boost the widespread use of high-pressure hydrogen systems (256). These targets, corresponding to a device compressing hydrogen from $10 \mathrm{MPa}$ to $87.5 \mathrm{MPa}$ and with a hydrogen flow rate of around $100 \mathrm{~kg} / \mathrm{h}$, are:

- uninstalled cost of the compressor system: $\$ 275,000$

- energy requirement: $1.6 \mathrm{kWh} / \mathrm{kg}$

- availability: $85 \%$

- annual maintenance cost: $4 \%$ of the uninstalled cost 
Hydrogen compressors available nowadays are potentially able to achieve these targets, but several drawbacks need to be preliminarily overcome.

The capital cost of a reciprocating compressor is commonly around $\$ 150,000(257)$, and is particularly affected by the operating and maintenance (O\&M) costs. The maintenance of valves, packing and piston rings to avoid leaks amount to approximately $90 \%$ of the overall maintenance costs (258). The O\&M cost is estimated at $5 \%$ of capital cost per year $(257,259)$. Despite the relatively high cost, hydrogen reciprocating compressors, as well as diaphragm compressors, have an average efficiency of around 45\% (260). Higher efficiencies can be reached by lowering the hydrogen flow rate, because of the decreased hydrogen leaks. Linear compressors can achieve higher efficiencies than the traditional reciprocating compressors, higher than $70 \%$, mainly by virtue of the lower friction losses (261). Better results can be even achieved with an ionic liquid piston compressor, which is able to compress hydrogen from $0.5 \mathrm{MPa}$ to $100 \mathrm{MPa}$ with only five steps and a specific energy consumption of around $2.7 \mathrm{kWh} / \mathrm{kg}(128)$, which is almost $25 \%$ of the specific energy consumption of a reciprocating compressor. An ionic liquid compressor does not have solid moving parts, thus there are neither friction losses nor leaks. Taking into account their very high efficiency, close to $70 \%$, and their reduced size and weight, it is obvious that the ionic liquid typology seems to be the most suitable out of all mechanical hydrogen compressors for achieving the aforementioned DOE targets.

Cryogenic pumps proved to be a good alternative to the traditional hydrogen compressors for several reasons. The first advantage obtained by compressing hydrogen in the liquid state through cryogenic pump is the high volumetric energy density, up to $80 \mathrm{~g} / \mathrm{L}$, producing a significant reduction of the storage vessels. Furthermore, the required compression energy is very low, almost $1 \%$ of the lower heating value of hydrogen, for a hydrogen compression up to $30 \mathrm{MPa}$ and a hydrogen flow rate of $100 \mathrm{~kg} / \mathrm{h}(262)$. Hydrogen leaks are reduced in a 
cryogenic vessel compared to a traditional gas vessel, thus decreasing the O\&M cost. Unfortunately, no available information about the cost of cryogenic compression exists in the open literature, thus a clear comparison between such compression method and the mechanical one can be only based on performances. Despite all the aforementioned advantages, it should be recalled that cryogenic compression requires preliminary hydrogen liquefaction. Hence, the energy consumption of $10-13 \mathrm{kWh} / \mathrm{kg}$ for hydrogen liquefaction must be taken into account in the evaluation of the overall energy cost of the process, thus reducing the efficiency of the overall process. Furthermore, liquid hydrogen delivery might represent a further restrictive factor.

The cost of a metal hydride system compressing hydrogen from $1 \mathrm{MPa}$ to $10 \mathrm{MPa}$ and with a hydrogen flow rate of $0.42 \mathrm{~m}^{3} / \mathrm{h}$ was estimated at $\$ 23,000$ compared to $\$ 27,000$ for a piston mechanical compressor (184). A recent study confirmed this cost difference (259). It was estimated that, for compressing hydrogen from $0.7 \mathrm{MPa}$ to $25 \mathrm{MPa}$, the capital cost of a metal hydride compressor is around $\$ 150,000$ compared to $\$ 170,000$ for a mechanical compressor operating in the same conditions. Furthermore, a significant reduction of electric drive power has also to be highlighted, as the metal hydride compressor needs only $0.5 \mathrm{~kW}$ compared to the $20 \mathrm{~kW}$ of the mechanical compressor. Several other advantages can be achieved by using a metal hydride compressor, first of all a dramatic reduction of the system volume and weight: $400 \mathrm{~L}$ and $100 \mathrm{~kg}$ for the metal hydride compressor vs. $6,000 \mathrm{~L}$ and 3,600 $\mathrm{kg}$ for the mechanical compressor. Moreover, lower O\&M costs can be reached because of the absence of moving units: an annual maintenance cost of around $\$ 1,000$ was estimated for a metal hydride compressor, compared to the $\$ 9,000$ of a mechanical compressor. However, the efficiency of a hydrogen metal hydride compressor hardly exceeds $25 \%$, with an average efficiency of around $10 \%$. It was estimated that a specific energy consumption around 6-7 $\mathrm{kWh} / \mathrm{kg}$ is required for a two-stage compressor; nevertheless, because of the unavoidable 
thermal losses, this value arises up to $10 \mathrm{kWh} / \mathrm{kg}$ (263), with a consequent dramatic reduction of the compression efficiency. Methods to reduce energy consumption, such as the use of waste and cheap heat are thus needed to achieve the DOE targets.

Electrochemical compressor proved to be the best-suited choice when low hydrogen rates are needed. Electrochemical compressors indeed show a very high efficiency and low cost especially for low-pressure applications, generally not exceeding $10 \mathrm{MPa}$. In general, the capital expenditure for an electrochemical compressor is in the range $\$ 170-1,700 / \mathrm{kg} / \mathrm{day}$, compared to the $\$ 2,300 / \mathrm{kg} /$ day of a mechanical compressor. Furthermore, the O\&M costs were also found to be lower $(<\$ 1 / \mathrm{kg}$ vs. $\$ 1.75-2.3 / \mathrm{kg})(264)$, due to the lower specific energy consumption, generally $<4 \mathrm{kWh} / \mathrm{kg}$. Indeed, the operating cost can decrease down to $\$ 0.5 / \mathrm{kg}$ due to several improvements achieved during the last years, such as the optimisation of the catalyst, the enhanced thermal management, the improved water management and the use of low-cost membranes. In this way, an O\&M cost of $\$ 3,400 /$ year can be achieved (265). The hydrogen electrochemical compressor also has a higher efficiency than a mechanical compressor, commonly higher than $60 \%$. However, even if the hydrogen electrochemical compressor exhibits many advantages, its use has to be limited to low-pressure applications in order to achieve high efficiencies. Nevertheless, when used upstream of a second compression stage, e.g. a thermally-driven compressor, electrochemical compressors can ensure a costeffective compression process (256).

Finally, the conception of a hydrogen adsorption compressor is still too recent to have detailed information about capital and operative costs, as well as about performances. In general, the costs of an adsorption compressor should be lower than those of a mechanical compressor: adsorption compressors do not have moving parts, thus no maintenance costs due to the wear of mechanical units have to be taken into account. Moreover, the volume of a hydrogen adsorption compressor can be significantly lower than the large volumes commonly 
used for the reciprocating compressors. Nevertheless, it should be considered that a hydrogen adsorption compressor works in a broad range of temperature, generally between $77 \mathrm{~K}$ and $298 \mathrm{~K}$, making the O\&M increase further. Indeed, beside the cost needed for cryogenic operation, the adsorption tank must withstand very low temperatures and high pressures, thus a periodic maintenance is necessary. Hence, a total cost slightly higher than a metal hydride compressor is expected.

\section{Conclusion}

Hydrogen use in stationary and automotive applications, such as fuel cells vehicles and hydrogen refuelling station above all, has shown to be hindered by its own volumetric energy density, the lowest one among all the common fuels nowadays used. In order to reach high storage levels, thus fostering hydrogen use as a renewable and sustainable fuel, compression seems to be the most efficient solution.

Hydrogen compression technologies are divided in two categories: mechanical and nonmechanical compression. The first group includes systems traditionally used for gas compression such as reciprocating, diaphragm, linear and liquid compressors. In all of them, hydrogen is confined into a closed volume, and compression is obtained through the decrease of this volume by means of a moving unit. The reciprocating compressor is the most used typology of compressor, and it ensures good performances especially for high-pressure applications. Diaphragm compressors are quite suitable in applications requiring low flows of hydrogen, while linear compressors are particularly used in aerospace applications and for electronics cooling. Innovative ionic liquid hydrogen compressors seem to be a very promising solution in the development of hydrogen refuelling stations in the frame of 
automotive applications, since they allow compressing hydrogen up to $100 \mathrm{MPa}$ through a system with a few moving units only.

The second group includes non-mechanical typologies of compressors, conceived specifically for hydrogen applications: cryogenic, metal hydride, electrochemical and adsorption compressors. Cryogenic compressors combine the benefits of both compression and liquefaction of hydrogen gas. Metal hydride compressors ensure at the same time safe hydrogen storage and compression; as they require heat exchange, they are known as thermally-driven compressors. Very good efficiencies can be achieved by using such devices, because of the higher energy densities potentially accessible and of the possibility of integrating them in industrial systems in which heat is produced. Electrochemical compressors are based on the use of selective polymeric membranes to compress gaseous hydrogen, and exhibit the highest compression efficiency among the current technologies used for hydrogen compression. Finally, adsorption compressors rely on the ability of hydrogen to bind weakly to the surface of high porous solids, such as carbonaceous materials or metal-organic frameworks. Enhanced energy densities are achieved especially when adsorption compressors operate at low temperature.

The availability of several hydrogen compression technologies makes possible the development of new innovative and environmental friendly solutions for the use of energy, leading to a transition towards a fossil fuel divestment and giving a critical contribution to the Sustainable Development.

\section{Acknowledgments}

This study was partly supported by the French PIA project "Lorraine Université d'Excellence", reference ANR-15-IDEX-04-LUE. 


\section{References}

1. Graetz J. New approaches to hydrogen storage. Chem Soc Rev. 2008;38(1):73-82.

2. Carmo M, Fritz DL, Mergel J, Stolten D. A comprehensive review on PEM water electrolysis. Int J Hydrog Energy. 2013;38(12):4901-34.

3. Hosseini SE, Wahid MA. Hydrogen production from renewable and sustainable energy resources: Promising green energy carrier for clean development. Renew Sustain Energy Rev. 2016 May 1;57:850-66.

4. Ausiello A, Micoli L, Turco M, Toscano G, Florio C, Pirozzi D. Biohydrogen production by dark fermentation of Arundo donax using a new methodology for selection of H2-producing bacteria. Int J Hydrog Energy. 2017;42(52):30599-612.

5. Lagorse J, Simões MG, Miraoui A, Costerg P. Energy cost analysis of a solar-hydrogen hybrid energy system for stand-alone applications. Int J Hydrog Energy. 2008;33(12):2871-9.

6. Barbir F. PEM electrolysis for production of hydrogen from renewable energy sources. Sol Energy. 2005;78(5):661-9.

7. Jain IP. Hydrogen the fuel for 21st century. Int J Hydrog Energy. 2009;34(17):7368-78.

8. Edwards PP, Kuznetsov VL, David WIF, Brandon NP. Hydrogen and fuel cells: Towards a sustainable energy future. Energy Policy. 2008;36(12):4356-62.

9. Agbossou K, Chahine R, Hamelin J, Laurencelle F, Anouar A, St-Arnaud J-M, et al. Renewable energy systems based on hydrogen for remote applications. J Power Sources. 2001;96(1):16872.

10. Edwards PP, Kuznetsov VL, David WIF. Hydrogen energy. Philos Trans R Soc Lond Math Phys Eng Sci. 2007;365:1043-56.

11. Bossel U. Does a Hydrogen Economy Make Sense? Proc IEEE. 2006;94(10):1826-37.

12. Sherif SA, Goswami DY, Stefanakos EK (Lee), Steinfeld A. Handbook of Hydrogen Energy. CRC Press; 2014.

13. Perry RH. Perry's Chemical Engineers' Handbook - Seventh Edition. McGraw-Hill; 1999.

14. Züttel A. Hydrogen storage methods. Naturwissenschaften. 2004;91(4):157-72.

15. Amos WA. Costs of Storing and Transporting Hydrogen [Internet]. National Renewable Energy Lab., Golden, CO (US); 1999 [cited 2017 Feb 27]. Report No.: NREL/TP-570-25106; ON: DE00006574. Available from: https://www.osti.gov/scitech/biblio/6574

16. Chilev C, Lamari FD. Hydrogen storage at low temperature and high pressure for application in automobile manufacturing. Int J Hydrog Energy. 2016;41(3):1744-58.

17. Hammerschlag R, Mazza P. Questioning hydrogen. Energy Policy. 2005;33(16):2039-43.

18. Das LM. On-board hydrogen storage systems for automotive application. Int J Hydrog Energy. 1996;21(9):789-800. 
19. Marbán G, Valdés-Solís T. Towards the hydrogen economy? Int J Hydrog Energy. 2007;32(12):1625-37.

20. Bossel U, Eliasson B, Taylor G. The Future of the Hydrogen Economy: Bright or Bleak? Cogener Compet Power J. 2003;18(3):29-70.

21. Yang C, Ogden J. Determining the lowest-cost hydrogen delivery mode. Int J Hydrog Energy. 2007;32(2):268-86.

22. Cipriani G, Di Dio V, Genduso F, La Cascia D, Liga R, Miceli R, et al. Perspective on hydrogen energy carrier and its automotive applications. Int J Hydrog Energy. 2014;39(16):8482-94.

23. Conte $\mathrm{M}$, lacobazzi $\mathrm{A}$, Ronchetti $\mathrm{M}$, Vellone R. Hydrogen economy for a sustainable development: state-of-the-art and technological perspectives. J Power Sources. 2001;100:171-87.

24. Godula-Jopek A. Hydrogen Production: by Electrolysis. John Wiley \& Sons; 2015.

25. Klebanoff LE, Keller JO. 5 Years of hydrogen storage research in the U.S. DOE Metal Hydride Center of Excellence (MHCoE). Int J Hydrog Energy. 2013;38(11):4533-76.

26. DOE Technical Targets for Onboard Hydrogen Storage for Light-Duty Vehicles | Department of Energy [Internet]. [cited 2017 Feb 28]. Available from: https://energy.gov/eere/fuelcells/doetechnical-targets-onboard-hydrogen-storage-light-duty-vehicles

27. Schaefer S, Fierro V, Izquierdo MT, Celzard A. Assessment of hydrogen storage in activated carbons produced from hydrothermally treated organic materials. Int J Hydrog Energy. 2016;41(28):12146-56.

28. Yang J, Sudik A, Wolverton C, Siegel DJ. High capacity hydrogen storage materials: attributes for automotive applications and techniques for materials discovery. Chem Soc Rev. 2010;39(2):656-75.

29. Kikukawa S, Yamaga F, Mitsuhashi H. Risk assessment of Hydrogen fueling stations for $70 \mathrm{MPa}$ FCVs. Int J Hydrog Energy. 2008;33(23):7129-36.

30. Huff H, Lindsay D, Radermacher R. Positive Displacement Compressor And Expander Simulation [Internet]. International Compressor Engineering Conference, Paper 1527; 2002 [cited 2017 Feb 25]. Available from: http://docs.lib.purdue.edu/icec/1527

31. Stolten D, Emonts B. Hydrogen Science and Engineering: Materials, Processes, Systems and Technology, 2 Volume. John Wiley \& Sons; 2016.

32. Hydro-Pac, INC. High pressure gas compressors, pumps and related products [Internet]. 2017 [cited 2017 Mar 16]. Available from: http://www.hydropac.com/hydrogen-compression.html

33. Bloch HP, Hoefner JJ. Reciprocating Compressors: Operation and Maintenance. Gulf Professional Publishing; 1996.

34. Pahwa PK, Pahwa GK. Hydrogen Economy. The Energy and Resources Institute (TERI); 2014. 
35. Kurita S, Arai S, Akanuma A, Fukai Y, Miura H. Hydrogen compressor system [Internet]. US8151834 B2, 2012 [cited 2017 Feb 2]. Available from:

http://www.google.ch/patents/US8151834

36. Horia Tierean M, Sanda Baltes L. Design of Valves Used in Reciprocating Compressors. Recent Adv Appl Theor Mech. 2009;138-43.

37. Almasi A. Reciprocating Compressor Optimum Design and Manufacturing with respect to Performance, Reliability and Cost. Int J Soc Behav Educ Econ Bus Ind Eng. 2009;3(4):243-8.

38. Dwivedi SN. Design Considerations for High-Pressure Reciprocating Compressors for Refinery Services [Internet]. International Compressor Engineering Conference, Paper 715; 1990 [cited 2017 Mar 14]. Available from: http://docs.lib.purdue.edu/icec/715

39. API Std 618. Reciprocating compressors for petroleum, chemical, and gas industry services, 4th Edition. American Petroleum Institute; 1995.

40. GE Oil \& Gas. Reciprocating Compression. High Speed Reciprocating Compressors (HSR) [Internet]. 2016 [cited 2018 Aug 25]. Available from:

https://www.geoilandgas.com/sites/geog/files/recip_overview_brochure_hsr_only.pdf

41. Gupta SK, McCormick CL, Melcher CW, Schalk JL. Debottlenecking Hydrogen Reciprocating Compressors and Synchronous Motors [Internet]. Texas A\&M University. Turbomachinery Laboratories; 2000 [cited 2017 Mar 3]. Available from: http://hdl.handle .net /1969.1/163349.

42. Almasi A. Latest practical notes and recent lessons learned on reciprocating compressors. Aust J Mech Eng. 2016;14(2):138-50.

43. Rangwala AS. Reciprocating Machinery Dynamics. New Age International; 2006.

44. LeBleu J Jr, Perez R. Operator's Guide to Rotating Equipment. AuthorHouse LLC; 2014.

45. Xin D, Feng J, Ding L, Yang D, Peng X. Experimental investigation of pressure distribution between the piston rings and its formation in reciprocating compressors. J Mech Eng Sci. 226(11):2701-12.

46. Yu W, Dianbo X, Jianmei F, Xueyuan P. Research on sealing performance and self-acting valve reliability in high-pressure oil-free hydrogen compressors for hydrogen refueling stations. Int J Hydrog Energy. 2010;35(15):8063-70.

47. Directive 94/9/EC of the European Parliament and the Council of 23 March 1994 on the approximation of the laws of the Member States concerning equipment and protective systems intended for use in potentially explosive atmospheres. Official Journal of the European Communities 1994.

48. Hitachi Infrastructure Systems (Asia) Pte. Ltd. High-Pressure Hydrogen Compressors (100MPaclass hydrogen compressors for hydrogen refueling stations) [Internet]. 2014 [cited $2017 \mathrm{Feb}$ 2]. Available from: http://www.hitachi-

infra.com.sg/services/_social_infrastructure_systems/compressor/reciprocating/hydrogen.ht $\mathrm{ml}$

49. Arjomand Kermani N, Rokni M. Heat transfer analysis of liquid piston compressor for hydrogen applications. Int J Hydrog Energy. 2015;40(35):11522-9. 
50. Tuhovcak J, Hejcik J, Jicha M. Comparison of heat transfer models for reciprocating compressor. Appl Therm Eng. 2016;103:607-15.

51. Shiddiqur Rahman M. Experimental and Numerical Study of Snuber in Hydrogen Compressor. Int J Sci Eng. 2012;3(2):21-5.

52. Leonard SM. Increase reliability of reciprocating hydrogen compressors. Hydrocarb Process. 1996;75:67-74.

53. Ahmed S, Sutherland E. 2013 Hydrogen Compression, Storage and Dispensing Cost Reduction Workshop Final Report [Internet]. U.S. Department of Energy Washington, D.C. 20585; 2013 [cited 2017 Feb 4]. Available from: https://www.energy.gov/eere/fuelcells/hydrogencompression-storage-and-dispensing-cost-reduction-workshop

54. Brown RN. Compressors. Selection and Sizing - Third Edition. Elsevier Inc. 2005.

55. Totten GE. Handbook of Lubrication and Tribology: Volume I Application and Maintenance, Second Edition. CRC Press; 2006.

56. Bloch HP. A practical guide to Compressor Technology - Second Edition. John Wiley \& Sons; 2006.

57. Pirro DM, Daschner E. Lubrication Fundamentals, Second Edition. CRC Press; 2001.

58. Zhang J. Improvement of Performance for Superhigh Pressure Diaphragm Compressor [Internet]. International Compressor Engineering Conference, Paper 691; 1990 [cited 2017 Mar 17]. Available from: http://docs.lib.purdue.edu/icec/691

59. Zhang J, Fisher TS, Ramachandran PV, Gore JP, Mudawar I. A Review of Heat Transfer Issues in Hydrogen Storage Technologies. J Heat Transf. 2005;127:1391-9.

60. Godula-Jopek A, Jehle W, Wellnitz J. Hydrogen Storage Technologies: New Materials, Transport, and Infrastructure. John Wiley \& Sons; 2012.

61. Hofer - Neuman \& Esser Group. Hofer diaphragm compressors [Internet]. 2015 [cited 2017 Jan 26]. Available from: http://www.andreas-hofer.de/en/products/diaphragmcompressors/examples/

62. Scott RB, Denton WH, Nicholls CM. Technology and Uses of Liquid Hydrogen. Pergamon Press Ltd.; 1964.

63. Jia X, Chen J, Wu H, Peng X. Study on the diaphragm fracture in a diaphragm compressor for a hydrogen refueling station. Int J Hydrog Energy. 2016;41(15):6412-21.

64. Roy A, Watson S, Infield DG. Comparison of electrical energy efficiency of atmospheric and high-pressure electrolysers. Int J Hydrog Energy. 2006;31(14):1964-79.

65. McKetta J. Encyclopedia of Chemical Processing and Design. Vol. 18. CRC Press; 1976.

66. Tzimas E, Filiou C, Peteves SD, Veyret JB. Hydrogen storage: state-of-the-art and future perspective. European Commission, Directorate-General, Joint Research Centre. 2003. 
67. Stolten D. Hydrogen and Fuel Cells: Fundamentals, Technologies and Applications. John Wiley \& Sons; 2010.

68. Jiahao C, Xiaohan J, Chuang X, Xueyuan P. Design and validation of new cavity profiles for diaphragm stress reduction in a diaphragm compressor. IOP Conf Ser Mater Sci Eng. 2015;90:012083.

69. Li J, Liang L, Jia X, Peng X. A new generatrix of the cavity profile of a diaphragm compressor. Proc Inst Mech Eng Part C J Mech Eng Sci. 2014;228(10):1754-66.

70. Li J, Jia X, Wu Z, Peng X. The cavity profile of a diaphragm compressor for a hydrogen refueling station. Int J Hydrog Energy. 2014;39(8):3926-35.

71. Jia X, Zhao Y, Chen J, Peng X. Research on the flowrate and diaphragm movement in a diaphragm compressor for a hydrogen refueling station. Int J Hydrog Energy.

2016;41(33):14842-51.

72. Mathew B, Hegab H. Analytical modeling of microscale diaphragm compressors. Appl Therm Eng. 2013;51:130-6.

73. Mathew B, Hegab H. Lumped model of MEMS diaphragm compressors. Energy Convers Manag. 2013;67:376-84.

74. Sathe AA, Groll EA, Garimella SV. Optimization of electrostatically actuated miniature compressors for electronics cooling. Int J Refrig. 2009;32(7):1517-25.

75. Sathe AA, Groll EA, Garimella SV. Analytical model for an electrostatically actuated miniature diaphragm compressor. J Micromechanics Microengineering. 2008;18:035010.

76. PDC Machines. Diaphragm Compressors [Internet]. [cited 2017 Feb 4]. Available from: http://03d379a.netsolhost.com/TestSite/diaphragm-compressors/

77. Rohatgi A, Johnson K. Investigation of H2 Diaphragm Compressors to Enable Low-Cost LongLife Operation. DOE Hydrogen and Fuel Cells Program FY 2013 Annual Progress Report; 2013.

78. Weinert JX, Shaojun L, Ogden JM, Jianxin M. Hydrogen refueling station costs in Shanghai. Inst Transp Stud. 2007;32:4089-100.

79. Liang K, Stone R, Dadd M, Bailey P. A novel linear electromagnetic-drive oil-free refrigeration compressor using R134a. Int J Refrig. 2014;40:450-9.

80. Ross RG. Cryocoolers 11. Springer Science \& Business Media; 2007.

81. Liang K. A review of linear compressors for refrigeration. Int J Refrig. 2017 Dec 1;84:253-73.

82. Broerman EL, Bennett J, Poerner N, Strickland D, Helffrich J, Coogan S, et al. Hydrogen Compression Application of the Linear Motor Reciprocating Compressor (LMRC). DOE Hydrogen and Fuel Cells Program. FY 2015 Annual Progress Report; 2015.

83. Shi Y, Li ZL. Research on Electric Linear Compressor for New Energy Vehicles. Adv Mater Res. 2012;383-390:5470-3. 
84. Van Der Walt NR, Unger R. Linear Compressors - A Maturing Technology. Int Appl Technol Conf May 9-11 1994. University of Wisconsin, Madison, WI.

85. Redlich R, Unger R, Van Der Walt N. Linear Compressors: Motor Configuration, Modulation and System [Internet]. International Compressor Engineering Conference. Paper 1129.; 1996 [cited 2017 Mar 16]. Available from: http://docs.lib.purdue.edu/icec/1129

86. Unger RL. Linear Compressors for Clean and Specialty Gases [Internet]. International Compressor Engineering Conference. Paper 1215; 1998 [cited 2107 Mar 16]. Available from: http://docs.lib.purdue.edu/icec/1215

87. Zhang L, Dang H, Tan J, Song Y, Zhou B, Zou R, et al. Theoretical and experimental investigations on the partial scaling method for the Oxford-type moving-coil linear compressor. Cryogenics. 2015;69:26-35.

88. Chen N, Tang YJ, Wu YN, Chen X, Xu L. Study on static and dynamic characteristics of moving magnet linear compressors. Cryogenics. 2007;47(9-10):457-67.

89. Nam J-W, Oh J-T, Kim G-S. A Study of Dynamic Performance Improvement of Linear Compressors Using Phase Control Loop. J Inst Electron Inf Eng. 2014;51(3):156-63.

90. Park K, Hong E, Lee HK. Linear Motor for Linear Compressor [Internet]. International Compressor Engineering Conference. Paper 1544.; 2002 [cited 2017 Mar 18]. Available from: http://docs.lib.purdue.edu/icec/1544

91. Yan P, Gao W, Chen G. Development of a linear compressor for two-stage pulse tube cryocoolers. J Zhejiang Univ-Sci A. 2009;10(11):1595-600.

92. Bhatt P. Maximum Marks Maximum Knowledge in Physics. Allied Publishers; 2008.

93. Chun TW, Ahn JR, Lee CW. Analysis and Control for Linear Compressor System Driven by PWM Inverter. 30th Annu Conf IEEE Ind Electron Soc. November 2-6, 2004, Busan, Korea.

94. Unger R, Novotny S. A High Performance Linear Compressor For CPU Cooling [Internet]. International Compressor Engineering Conference. Paper 1603; 2002 [cited 2017 Mar 20]. Available from: http://docs.lib.purdue.edu/icec/1603

95. Dainez PS, de Oliveira J, Nied A, Cavalca MSM. A linear resonant compressor model based on a new linearization method of the gas pressure force. Int J Refrig. 2014;48:201-9.

96. Sevekari MG, Phadkule S, Bhojwani V, Jomde A, Deshmukh S. Modelling And Analysis of Linear Compressor. Int J Mech Eng Comput Appl. 2014;1(7):157-62.

97. Liang K, Stone R, Dadd M, Bailey P. Piston position sensing and control in a linear compressor using a search coil. Int J Refrig. 2016;66:32-40.

98. Sung JW, Lee CW, Kim G-S, Lipo TA, Won C-Y, Choi S. Sensorless control for linear compressors. Int J Appl Electromagn Mech. 2006;24(3-4):273-86.

99. Kim JK, Jeong JH. Dynamic response of a capacity-modulated linear compressor to supply voltage disturbances. Int J Refrig. 2014;40:84-96. 
100. Bradshaw CR, Groll EA, Garimella SV. A comprehensive model of a miniature-scale linear compressor for electronics cooling. Int J Refrig. 2011;34(1):63-73.

101. Humphrey HA. An Internal-combustion Pump, and Other Applications of a New Principle. Proc Inst Mech Eng. 1909;77(1):1075-200.

102. Van de Ven JD, Li PY. Liquid piston gas compression. Appl Energy. 2009;86(10):2183-91.

103. Petrescu S, Torok A, Popescu G, Feidt M. Quasi-Isothermal Compressors and Expanders With Liquid Piston. In: Advanced Thermodynamics of Irreversible Processes with Finite Speed and Finite Dimensions A historical and epistemological approach, with extension to biological and social systems. I Edition. AGIR Publishing House Calea Victoriei; 2015.

104. Heidari M, Lemofouet S, Rufer A. On The Strategies Towards Isothermal Gas Compression And Expansion [Internet]. International Compressor Engineering Conference. Paper 2285; 2014 [cited 2017 Feb 5]. Available from: http://docs.lib.purdue.edu/icec/2285

105. Li PY, Saadat M. An approach to reduce the flow requirement for a liquid piston nearisothermal air compressor/expander in a compressed air energy storage system. IET Renew Power Gener. 2016;10(10):1506-14.

106. Lemofouet S, Rufer A. Hybrid energy storage systems based on compressed air and supercapacitors with maximum efficiency point tracking. IEEE Trans Ind Electron. 2006;53(4):1105-15.

107. Saadat M, Li PY, Simon TW. Optimal trajectories for a liquid piston compressor/expander in a compressed air energy storage system with consideration of heat transfer and friction. 2012 Am Control Conf ACC 27-29 June 2012. Montreal, QC, Canada.

108. Mutlu M, Kiliç M. Effects of piston speed, compression ratio and cylinder geometry on system performance of a liquid piston. Therm Sci. 2016;20(6):1953-61.

109. Zhang C, Yan B, Wieberdink J, Li PY, Van de Ven JD, Loth E, et al. Thermal analysis of a compressor for application to Compressed Air Energy Storage. Appl Therm Eng. 2014;73(2):1402-11.

110. Park J, Ro PI, He X, Mazzoleni AP. Analysis, Fabrication, and Testing of a Liquid Piston Compressor Prototype for an Ocean Compressed Air Energy Storage (OCAES) System. Mar Technol Soc J. 2014;48(6):86-97.

111. Zhang C, Wieberdink JH, Shirazi FA, Yan B, Simon TW, Li PY. Numerical investigation of metalfoam filled liquid piston compressor using a two-energy equation formulation based on experimentally validated models. Proc ASME 2013 Int Mech Eng Congr Expo Novemb 15-21 2013. San Diego, California, USA.

112. Yan B, Wieberdink J, Shirazi F, Li PY, Simon TW, Van de Ven JD. Experimental study of heat transfer enhancement in a liquid piston compressor/expander using porous media inserts. Appl Energy. 2015;154:40-50.

113. Yang S, Zhou S, Sun S. Internal Water-Spray Cooling in the Reciprocating Compressor [Internet]. International Compressor Engineering Conference, Paper 669; 1988 [cited 2017 Feb 6]. Available from: http://docs.lib.purdue.edu/icec/669 
114. Saadat M, Shirazi FA, Li PY. Modeling and trajectory optimization of water spray cooling in a liquid piston air compressor. Proc ASME 2013 Heat Transf Summer Conf July 14-19 2013. Minneapolis, MN, USA.

115. Lyons WC, Plisga GJ, Lorenz MD. Standard Handbook of Petroleum and Natural Gas Engineering. Gulf Professional Publishing; 2015.

116. Lyons WC. Air and Gas Drilling Manual: Applications for Oil and Gas Recovery Wells and Geothermal Fluids Recovery Wells. Third Edition. Gulf Professional Publishing; 2009.

117. Forsthoffer WE. Forsthoffer's Best Practice Handbook for Rotating Machinery. Elsevier; 2011.

118. Liptak BG. Instrument Engineers' Handbook, Fourth Edition, Volume Two: Process Control and Optimization. CRC Press; 2005.

119. Forsthoffer WE. Forsthoffer's Rotating Equipment Handbooks: Compressors. Vol. 3. Elsevier; 2005.

120. Weingärtner H. Understanding Ionic Liquids at the Molecular Level: Facts, Problems, and Controversies. Angew Chem Int Ed. 2008;47(4):654-70.

121. Armand $M$, Endres F, MacFarlane DR, Ohno H, Scrosati B. Ionic-liquid materials for the electrochemical challenges of the future. Nat Mater. 2009;8(8):621-9.

122. Predel T, Schlücker E, Wasserscheid P, Gerhard D, Arlt W. Ionic Liquids as Operating Fluids in High Pressure Applications. Chem Eng Technol. 2007;30(11):1475-80.

123. MacFarlane DR, Tachikawa N, Forsyth M, Pringle JM, Howlett PC, Elliott GD, et al. Energy applications of ionic liquids. Energy Env Sci. 2014;7(1):232-50.

124. Plechkova NV, Seddon KR. Ionic Liquids Completely UnCOILed: Critical Expert Overviews. John Wiley \& Sons; 2015.

125. Lei Z, Dai C, Chen B. Gas Solubility in Ionic Liquids. Chem Rev. 2014;114(2):1289-326.

126. Schluecker E, Szarvas L, Uerdingen E. New developments in pumps and compressors using ionic liquids. ACHEMA World Wide News. 2008;5-7.

127. Natesan N. Fuel Cell Bus Workshop - Linde H2 Fueling. September 17, 2013. Diamond Bar, CA. [cited 2017 Mar 7]; Available from: https://www.arb.ca.gov/msprog/bus/zbus/workshop/3d_Natesan.pdf

128. Mayer M. From Prototype to Serial Production. Manufacturing Hydrogen Fuelling Stations. A3PS Conference 2014 [Internet]. [cited 2017 Mar 10]. Available from:

http://www.a3ps.at/sites/default/files/conferences/2014/papers/01_linde_mayer.pdf

129. Kermani NA, Petrushina I, Nikiforov A, Jensen JO, Rokni M. Corrosion behavior of construction materials for ionic liquid hydrogen compressor. Int J Hydrog Energy. 2016;41(38):16688-95.

130. Tao $\mathrm{Y}$, Hwang $\mathrm{Y}$, Radermacher $\mathrm{R}$, Wang $\mathrm{C}$. Performance Investigation on Electrochemical Compressor with Ammonia [Internet]. International Compressor Engineering Conference. Paper 2469; 2016 [cited 2017 Feb 14]. Available from: http://docs.lib.purdue.edu/icec/2469 
131. Wical B. Total Energy Independence for the United States: A Twelve-year Plan. iUniverse; 2007.

132. Rohland B, Eberle K, Ströbel R, Scholta J, Garche J. Electrochemical hydrogen compressor. Electrochimica Acta. 1998;43(24):3841-6.

133. Aceves S, Petitpas G. Performance and durability testing of volumetrically efficient cryogenic vessels and high pressure liquid hydrogen pump. DOE hydrogen and fuel cells program review; 2016.

134. Aceves SM, Berry GD, Martinez-Frias J, Espinosa-Loza F. Vehicular storage of hydrogen in insulated pressure vessels. Int J Hydrog Energy. 2006;31(15):2274-83.

135. Petitpas G, Bénard P, Klebanoff LE, Xiao J, Aceves S. A comparative analysis of the cryocompression and cryo-adsorption hydrogen storage methods. Int J Hydrog Energy. 2014;39(20):10564-84.

136. Aceves SM, Petitpas G, Espinosa-Loza F, Matthews MJ, Ledesma-Orozco E. Safe, long range, inexpensive and rapidly refuelable hydrogen vehicles with cryogenic pressure vessels. Int J Hydrog Energy. 2013;38(5):2480-9.

137. Aceves SM, Berry GD, Rambach GD. Insulated pressure vessels for hydrogen storage on vehicles. Int J Hydrog Energy. 1998;23(7):583-91.

138. Grasman SE. Hydrogen Energy and Vehicle Systems. CRC Press; 2012.

139. Aceves SM, Espinosa-Loza F, Ledesma-Orozco E, Ross TO, Weisberg AH, Brunner TC, et al. High-density automotive hydrogen storage with cryogenic capable pressure vessels. Int J Hydrog Energy. 2010;35(3):1219-26.

140. Paggiaro R, Benard P, Polifke W. Cryo-adsorptive hydrogen storage on activated carbon. I: Thermodynamic analysis of adsorption vessels and comparison with liquid and compressed gas hydrogen storage. Int J Hydrog Energy. 2010 Jan;35(2):638-47.

141. Air Product. The Cryogenic Hydrogen Compressor system [Internet]. [cited 2017 Feb 27]. Available from: http://www.airproducts.com/ /media/downloads/h/hydrogen-supportmicrosite/en-cryogenic-hydrogen-compressor-system.pdf?la=en

142. Ahluwalia RK, Hua TQ, Peng J-K, Lasher S, McKenney K, Sinha J, et al. Technical assessment of cryo-compressed hydrogen storage tank systems for automotive applications. Int J Hydrog Energy. 2010;35(9):4171-84.

143. Hübert T, Boon-Brett L, Buttner W. Sensors for Safety and Process Control in Hydrogen Technologies. CRC Press; 2016.

144. Hardy B, Corgnale C, Chahine R, Richard M-A, Garrison S, Tamburello D, et al. Modeling of adsorbent based hydrogen storage systems. Int J Hydrog Energy. 2012;37(7):5691-705.

145. Brunner T, Kampitsch M, Kircher O. Cryo-compressed Hydrogen Storage. In: Fuel Cells: Data, Facts and Figures. Wiley-Blackwell; 2016. p. 162-73.

146. Hwang HT, Varma A. Hydrogen storage for fuel cell vehicles. Curr Opin Chem Eng. 2014;5:428. 
147. Ahluwalia RK, Peng JK, Roh HS, Hua TQ, Houchins C, James BD. Supercritical cryo-compressed hydrogen storage for fuel cell electric buses. Int J Hydrog Energy. 2018;43(22):10215-31.

148. Kunze K, Kircher O. Cryo-Compressed Hydrogen Storage. BMW Group. Cryogenic Cluster Day, Oxford. September 28, 2012. [cited 2017 Apr 3]; Available from: https://www.stfc.ac.uk/stfc/cache/file/F45B669C-73BF-495B-B843DCDF50E8B5A5.pdf

149. Léon A. Hydrogen Technology: Mobile and Portable Applications. Springer Science \& Business Media; 2008.

150. Vanmal H. Chem Eng Tech. 1973;45:80.

151. Bhuiya MMH, Kim KJ. Performance study of a hydrogen powered metal hydride actuator. Smart Mater Struct. 2016;25(4):045004.

152. Lototskyy MV, Yartys VA, Pollet BG, Bowman RC. Metal hydride hydrogen compressors: A review. Int J Hydrog Energy. 2014;39(11):5818-51.

153. Yang FS, Wang GX, Zhang ZX, Meng XY, Rudolph V. Design of the metal hydride reactors - A review on the key technical issues. Int J Hydrog Energy. 2010;35(8):3832-40.

154. Dornheim M. Thermodynamics of Metal Hydrides: Tailoring Reaction Enthalpies of Hydrogen Storage Materials. In: Thermodynamics-interaction studies--solids, liquids and gases. INTECH Open Access Publisher; 2011. p. 891-918.

155. Murthy SS. Heat and mass transfer in solid state hydrogen storage: a review. J Heat Transf. 2012;134(3):031020.

156. Dehouche Z, Grimard N, Laurencelle F, Goyette J, Bose TK. Hydride alloys properties investigations for hydrogen sorption compressor. J Alloys Compd. 2005;399(1-2):224-36.

157. Koultoukis ED, I Gkanas E, Makridis SS, Christodoulou CN, Fruchart D, Stubos AK. Hightemperature activated $\mathrm{AB} 2$ nanopowders for metal hydride hydrogen compression: Metal hydride technology in hydrogen compression. Int J Energy Res. 2014;38(4):477-86.

158. Muthukumar P, Prakashmaiya M, Srinivasamurthy S. Performance tests on a thermally operated hydrogen compressor. Int J Hydrog Energy. 2008;33(1):463-9.

159. Wang $X$, Bei $Y$, Song $X$, Fang G, Li S, Chen C, et al. Investigation on high-pressure metal hydride hydrogen compressors. Int J Hydrog Energy. 2007;32(16):4011-5.

160. Sekhar BS, Muthukumar P. Development of Double-Stage Metal Hydride-Based Hydrogen Compressor for Heat Transformer Application. J Energy Eng. 2015;141(4):04014049.

161. Solovey VV, Ivanovsky Al, Kolosov VI, Shmal'ko YF. Series of metal hydride high pressure hydrogen compressors. J Alloys Compd. 1995;231(1):903-6.

162. Wang X, Liu H, Li H. A 70 MPa hydrogen-compression system using metal hydrides. Int J Hydrog Energy. 2011;36(15):9079-85.

163. Li H, Wang X, Dong Z, Xu L, Chen C. A study on 70MPa metal hydride hydrogen compressor. J Alloys Compd. 2010;502(2):503-7. 
164. Muthukumar P, Prakash Maiya M, Murthy SS. Parametric studies on a metal hydride based single stage hydrogen compressor. Int J Hydrog Energy. 2002;27(10):1083-92.

165. Wang X, Chen R, Zhang Y, Chen C, Wang Q. Hydrogen storage properties of (La-Ce-Ca)Ni5 alloys and application for hydrogen compression. Mater Lett. 2007;61(4-5):1101-4.

166. Bhuiya MMH, Lee CY, Hwang T, Munira S, Hopkins R, Yoon H, et al. Experimentally tuned dual stage hydrogen compressor for improved compression ratio. Int J Hydrog Energy. 2014;39(24):12924-33.

167. Pickering L, Reed D, Bevan Al, Book D. Ti-V-Mn based metal hydrides for hydrogen compression applications. J Alloys Compd. 2015;645:S400-3.

168. Bowman RC, Lynch FE, Marmaro RW, Luo CH, Fultz B, Cantrell JS, et al. Effects of thermal cycling on the physical properties of VHx. Z Phys Chem. 1993;181:269-73.

169. Wang X, Chen R, Chen C, Wang Q. Hydrogen storage properties of TixFe+ywt.\% La and its use in metal hydride hydrogen compressor. J Alloys Compd. 2006;425(1-2):291-5.

170. Kang BH, Yabe A. Performance analysis of a metal-hydride heat transformer for waste heat recovery. Appl Therm Eng. 1996;16(8):677-90.

171. Madaria Y, Anil Kumar E. Effect of heat transfer enhancement on the performance of metal hydride based hydrogen compressor. Int J Hydrog Energy. 2016;41(6):3961-73.

172. Koultoukis ED, Makridis SS, Fruchart D, Stubos AK. Two-Stage Hydrogen Compression Using ZrBased Metal Hydrides. Solid State Phenom. 2012;194:249-53.

173. Kelly NA, Girdwood R. Evaluation of a thermally-driven metal-hydride-based hydrogen compressor. Int J Hydrog Energy. 2012;37(14):10898-916.

174. Lototskyy MV, Tolj I, Davids MW, Klochko YV, Parsons A, Swanepoel D, et al. Metal hydride hydrogen storage and supply systems for electric forklift with low-temperature proton exchange membrane fuel cell power module. Int J Hydrog Energy. 2016;41(31):13831-42.

175. Yartys VA, Lototskyy M, Linkov V, Grant D, Stuart A, Eriksen J, et al. Metal hydride hydrogen compression: recent advances and future prospects. Appl Phys A. 2016;122(4).

176. Muthukumar P, Prakashmaiya M, Srinivasamurthy S. Experiments on a metal hydride based hydrogen compressor. Int J Hydrog Energy. 2005;30(8):879-92.

177. MacDonald BD, Rowe AM. A thermally coupled metal hydride hydrogen storage and fuel cell system. J Power Sources. 2006;161(1):346-55.

178. Kim J, Park I-S, Kim KJ, Gawlik K. A hydrogen-compression system using porous metal hydride pellets of LaNi5-xAlxLaNi5-xAlx. Int J Hydrog Energy. 2008;33(2):870-7.

179. Galvis E AR, Leardini F, Bodega J, Ares JR, Fernandez JF. Realistic simulation in a single stage hydrogen compressor based on AB2 alloys. Int J Hydrog Energy. 2016;41(23):9780-8.

180. Nasako $\mathrm{K}$, Ito $\mathrm{Y}$, Hiro N, Osumi M. Stress on a reaction vessel by the swelling of a hydrogen absorbing alloy. J Alloys Compd. 1998;264(1-2):271-6. 
181. Prabhukhot Prachi R, Wagh Mahesh M, Gangal Aneesh C. A Review on Solid State Hydrogen Storage Material. Adv Energy Power. 2016;4(2):11-22.

182. Shmalko YF, Ivanovsky A i, Lototsky MV, Kolosov V i, Volosnikov DV. Sample pilot plant of industrial metal-hydride compressor. Int J Hydrog Energy. 1999;24(7):645-8.

183. Shmalko YF, Ivanovsky A i, Lototsky MV, Karnatsevich LV, Milenko YY. Cryo-hydride highpressure hydrogen compressor. Int J Hydrog Energy. 1999;24(7):649-50.

184. Da Silva EP. Industrial prototype of a hydrogen compressor based on metallic hydride technology. Int J Hydrog Energy. 1993;18(4):307-11.

185. Bhuiya MMH, Lee CY, Hopkins R, Yoon H, Kim S, Park SH, et al. A High-Performance Dual-Stage Hydrogen Compressor System Using Ca0.2Mm0.8Ni5 Metal Hydride. ASME 2011 Conf Smart Mater Adapt Struct Intell Syst. 2011 Jan 1;745-51.

186. Lototskyy M, Klochko Y, Linkov V, Lawrie P, Pollet BG. Thermally Driven Metal Hydride Hydrogen Compressor for Medium-Scale Applications. Energy Procedia. 2012;29:347-56.

187. Hu X, Qi Z, Yang M, Chen J. A 38 MPa compressor based on metal hydrides. J Shanghai Jiaotong Univ Sci. 2012;17(1):53-7.

188. Ströbel R, Oszcipok M, Fasil M, Rohland B, Jörissen L, Garche J. The compression of hydrogen in an electrochemical cell based on a PE fuel cell design. J Power Sources. 2002;105(2):208-15.

189. Sedlak JM, Austin JF, LaConti AB. Hydrogen recovery and purification using the solid polymer electrolyte electrolysis cell. Int J Hydrog Energy. 1981;6(1):45-51.

190. Tao $\mathrm{Y}$, Lee $\mathrm{H}$, Hwang $\mathrm{Y}$, Radermacher R, Wang C. Electrochemical compressor driven metal hydride heat pump. Int J Refrig. 2015;60:278-88.

191. HyET | Hydrogen Efficiency Technologies [Internet]. [cited 2017 Mar 15]. Available from: http://www.hyet.nl/newsite/technology/working-principle

192. Revie RW. Corrosion and Corrosion Control. John Wiley \& Sons; 2008.

193. Abdin Z, Webb CJ, Gray EM. PEM fuel cell model and simulation in Matlab-Simulink based on physical parameters. Energy. 2016;116:1131-44.

194. Pasierb P, Rekas M. High-Temperature Electrochemical Hydrogen Pumps and Separators. Int J Electrochem. 2011;2011:1-10.

195. Casati C, Longhi P, Zanderighi L, Bianchi F. Some fundamental aspects in electrochemical hydrogen purification/compression. J Power Sources. 2008;180(1):103-13.

196. Fishel K, Qian G, Eisman G, Benicewicz BC. Electrochemical Hydrogen Pumping. In: Li Q, Aili D, Hjuler HA, Jensen JO, editors. High Temperature Polymer Electrolyte Membrane Fuel Cells. Springer International Publishing; 2016. p. 527-40.

197. Hernández-Flores G, Poggi-Varaldo HM, Solorza-Feria O. Comparison of alternative membranes to replace high cost Nafion ones in microbial fuel cells. Int J Hydrog Energy. 2016;41(48):23354-62. 
198. Feng M, Qu R, Wei Z, Wang L, Sun P, Wang Z. Characterization of the thermolysis products of Nafion membrane: A potential source of perfluorinated compounds in the environment. Sci Rep. 2015 May 7;5:9859.

199. Wu X, He G, Yu L, Li X. Electrochemical Hydrogen Pump with SPEEK/CrPSSA SemiInterpenetrating Polymer Network Proton Exchange Membrane for $\mathrm{H}_{2} / \mathrm{CO}_{2}$ Separation. ACS Sustain Chem Eng. 2014;2(1):75-9.

200. Maruyama R. Electrochemical Hydrogen Storage into LaNi5 Using a Fullerene-Based Proton Conductor. Electrochem Solid-State Lett. 2002;5(5):A89.

201. Ciureanu M, Mikhailenko SD, Kaliaguine S. PEM fuel cells as membrane reactors: kinetic analysis by impedance spectroscopy. Catal Today. 2003;82(1-4):195-206.

202. Chen W, Cameron B, Narayanan S. A Cryocooler Driven by Electrochemical Compressors with No Moving Parts. International Cryocooler Conference, Inc. Boulder, CO, 2014.

203. Grigoriev SA, Shtatniy IG, Millet P, Porembsky VI, Fateev VN. Description and characterization of an electrochemical hydrogen compressor/concentrator based on solid polymer electrolyte technology. Int J Hydrog Energy. 2011;36(6):4148-55.

204. Barbir F, Görgün H. Electrochemical hydrogen pump for recirculation of hydrogen in a fuel cell stack. J Appl Electrochem. 2007;37(3):359-65.

205. Najdi RA, Shaban TG, Mourad MJ, Karaki SH. Hydrogen production and filling of fuel cell cars. In: 2016 3rd International Conference on Advances in Computational Tools for Engineering Applications (ACTEA). 2016. p. 43-8.

206. Wong T, Girard F, Vanderhoek T. Electrochemical hydrogen compressor [Internet]. [cited 2017 Feb 14]. Available from: http://www.google.com/patents/US20040211679

207. Bouwman PJ, Konink J, Semerel D, Raymakers L, Koeman M, Kout W, et al. Electrochemical Hydrogen Compression. ECS Trans. 2014 Aug 18;64(3):1009-18.

208. Patel P, Lipp L. Electrochemical Hydrogen Compressor. DOE Hydrogen Compression, Storage and Dispensing Workshop at ANL. Argonne, IL. March 20, 2013.

209. Moton JM, James BD, Colella WG. Advances in Electrochemical Compression of Hydrogen. Proceedings of the ASME 2014 12th International Conference on Fuel Cell Science, Engineering and Technology. June 30, 2014. Boston, Massachusetts, USA.

210. Suermann M, Kiupel T, Schmidt TJ, Büchi FN. Electrochemical Hydrogen Compression: Efficient Pressurization Concept Derived from an Energetic Evaluation. J Electrochem Soc. 2017;164(12):F1187-95.

211. Onda K, Ichihara K, Nagahama M, Minamoto Y, Araki T. Separation and compression characteristics of hydrogen by use of proton exchange membrane. J Power Sources. 2007;164(1):1-8.

212. Sattler KD. Carbon Nanomaterials Sourcebook: Nanoparticles, Nanocapsules, Nanofibers, Nanoporous Structures, and Nanocomposites. Vol. II. CRC Press; 2016. 
213. Santori G, Luberti M. Thermodynamics of thermally-driven adsorption compression. Sustain Mater Technol. 2016;10:1-9.

214. Rosi NL, Eckert J, Eddaoudi M, Vodak DT, Kim J, O’Keeffe M, et al. Hydrogen Storage in Microporous Metal-Organic Frameworks. Science. 2003;300(5622):1127-9.

215. Li Y, Yang RT. Gas Adsorption and Storage in Metal-Organic Framework MOF-177. Langmuir. 2007;23(26):12937-44.

216. Panella B, Hirscher M, Pütter H, Müller U. Hydrogen Adsorption in Metal-Organic Frameworks: Cu-MOFs and Zn-MOFs Compared. Adv Funct Mater. 2006;16(4):520-4.

217. Züttel A. Materials for hydrogen storage. Mater Today. 2003 Sep;6(9):24-33.

218. Schaefer S, Fierro V, Szczurek A, Izquierdo MT, Celzard A. Physisorption, chemisorption and spill-over contributions to hydrogen storage. Int J Hydrog Energy. 2016;41(39):17442-52.

219. Sircar S, Hufton JR. Why Does the Linear Driving Force Model for Adsorption Kinetics Work? Adsorption. 2000;6(2):137-47.

220. Panella $B$, Hirscher $M$, Roth $\mathrm{S}$. Hydrogen adsorption in different carbon nanostructures. Carbon. 2005;43(10):2209-14.

221. Suh MP, Park HJ, Prasad TK, Lim D-W. Hydrogen storage in metal-organic frameworks. Chem Rev. 2012;112(2):782-835.

222. Sdanghi G, Maranzana G, Celzard A, Fierro V. Hydrogen Adsorption on Nanotextured Carbon Materials. In: Hydrogen Storage Technologies. Wiley-Blackwell; 2018. p. 263-320.

223. Kojima Y, Kawai Y, Koiwai A, Suzuki N, Haga T, Hioki T, et al. Hydrogen adsorption and desorption by carbon materials. J Alloys Compd. 2006;421(1):204-8.

224. Fierro V, Szczurek A, Zlotea C, Marêché JF, Izquierdo MT, Albiniak A, et al. Experimental evidence of an upper limit for hydrogen storage at $77 \mathrm{~K}$ on activated carbons. Carbon. 2010;48(7):1902-11.

225. de la Casa-Lillo MA, Lamari-Darkrim F, Cazorla-Amorós D, Linares-Solano A. Hydrogen Storage in Activated Carbons and Activated Carbon Fibers. J Phys Chem B. 2002;106(42):10930-4.

226. Chakraborty A, Kumar S. Thermal management and desorption modeling of a cryo-adsorbent hydrogen storage system. Int J Hydrog Energy. 2013;38(10):3973-86.

227. Wang H, Miller DC. Thermal Management and Enhancement of Adsorption Based Onboard Hydrogen Storage System. Proceedings of the ASME 2016 10th International Conference on Energy Sustainability. June 26-30, 2016, Charlotte, North Carolina.

228. Bénard $P$, Chahine R. Storage of hydrogen by physisorption on carbon and nanostructured materials. Scr Mater. 2007;56(10):803-8.

229. Koley S, Ghosh I. New technique for generating continuous sorption cooling in a single adsorbent column. Appl Therm Eng. 2013;55(1-2):33-42. 
230. Luo BJ, Wang ZL, Yan T, Hong GT, Li YL, Liang JT. A non-lumped dynamic simulation method of sorption compressor for sorption cryocooler. Cryogenics. 2013;58:14-9.

231. Xiao J, Bénard P, Chahine R. Charge-discharge cycle thermodynamics for compression hydrogen storage system. Int J Hydrog Energy. 2016;41(12):5531-9.

232. Xiao J, Yang H, Bénard P, Chahine R. Numerical study of thermal effects in cryo-adsorptive hydrogen storage tank. J Renew Sustain Energy. 2013;5(2):021414.

233. Hermosilla-Lara G, Momen G, Marty PH, Le Neindre B, Hassouni K. Hydrogen storage by adsorption on activated carbon: Investigation of the thermal effects during the charging process. Int J Hydrog Energy. 2007;32(10-11):1542-53.

234. Tong L, Xiao J, Cai Y, Bénard $P$, Chahine R. Thermal effect and flow-through cooling of an adsorptive hydrogen delivery tank. Int J Hydrog Energy. 2016;41(36):16094-100.

235. Delahaye A, Aoufi A, Gicquel A, Pentchev I. Improvement of hydrogen storage by adsorption using 2-D modeling of heat effects. AIChE J. 2002;48(9):2061-73.

236. Xiao J, Peng R, Cossement $D$, Bénard $P$, Chahine R. Heat and mass transfer and fluid flow in cryo-adsorptive hydrogen storage system. Int J Hydrog Energy. 2013;38(25):10871-9.

237. Noh JS, Agarwal RK, Schwarz JA. Hydrogen storage systems using activated carbon. Int J Hydrog Energy. 1987;12(10):693-700.

238. Zhao W, Fierro V, Aylon E, Izquierdo MT, Celzard A. High-performances carbonaceous adsorbents for hydrogen storage. J Phys Conf Ser. 2013;416:012024.

239. Zhao W, Fierro V, Zlotea C, Aylon E, Izquierdo MT, Latroche M, et al. Optimization of activated carbons for hydrogen storage. Int J Hydrog Energy. 2011;36:11746-51.

240. Tellez-Juarez MC, Fierro V, Zhao W, Fernandez-Huerta N, Izquierdo MT, Reguera E, et al. Hydrogen storage in activated carbons produced from coals of different ranks: Effect of oxygen content. Int J Hydrog Energy. 2014;39(10):4996-5002.

241. Zhou L, Zhou Y, Sun Y. Enhanced storage of hydrogen at the temperature of liquid nitrogen. Int J Hydrog Energy. 2004;29(3):319-22.

242. Simonovski I, Baraldi D, Melideo D, Acosta-lborra B. Thermal simulations of a hydrogen storage tank during fast filling. Int J Hydrog Energy. 2015;40(36):12560-71.

243. Ahluwalia RK, Peng JK. Automotive hydrogen storage system using cryo-adsorption on activated carbon. Int J Hydrog Energy. 2009;34(13):5476-87.

244. Richard M-A, Cossement D, Chandonia P-A, Chahine R, Mori D, Hirose K. Preliminary evaluation of the performance of an adsorption-based hydrogen storage system. AIChE J. 2009;55(11):2985-96.

245. Chahine R, Bose TK. Low-pressure adsorption storage of hydrogen. Int J Hydrog Energy. 1994;19(2):161-4.

246. Fierro V, Zhao W, Izquierdo MT, Aylon E, Celzard A. Adsorption and compression contributions to hydrogen storage in activated anthracites. Int J Hydrog Energy. 2010;35(17):9038-45. 
247. Rouhani M, Huttema W, Bahrami M. Effective thermal conductivity of packed bed adsorbers: Part 1 - Experimental study. Int J Heat Mass Transf. 2018;123:1204-11.

248. Wang LW, Tamainot-Telto Z, Thorpe R, Critoph RE, Metcalf SJ, Wang RZ. Study of thermal conductivity, permeability, and adsorption performance of consolidated composite activated carbon adsorbent for refrigeration. Renew Energy. 2011;36(8):2062-6.

249. Hahne E, Kallweit J. Thermal conductivity of metal hydride materials for storage of hydrogen: Experimental investigation. Int J Hydrog Energy. 1998;23(2):107-14.

250. Wade LA. An Overview of the Development of Sorption Refrigeration. In: Fast RW, editor. Advances in Cryogenic Engineering. Springer US; 1992. p. 1095-106.

251. Swain S, Ghosh I. Conceptual design analysis of a compressor-driven sorption cooling system. Int J Energy Res. 2010;34(11):1016-26.

252. Zheng W, Worek WM, Nowakowski G. Performance of multi-bed sorption heat pump systems. Int J Energy Res. 1996;20(4):339-50.

253. Luo BJ, Wang ZL, Yan T, Hong GT, Li YL, Liang JT. Theoretical study of effect of working fluid on the performance of 77-100K adsorption cryocooler. Energy Convers Manag. 2015;89:919-24.

254. Wu Y, Mulder T, Vermeer CH, Holland HJ, Benthem B, ter Brake HJM. Vibration-free Cooler for the METIS Instrument Using Sorption Compressors. Phys Procedia. 2015;67:411-6.

255. Alvarez JA, Krylo RJ, Snapp RD, Weston C, Sywulka P, Abell GC. Development of an Advanced Sorption Compressor and Its Application in a $125 \mathrm{~K}$ Cryocooler. In: Jr RGR, editor. Cryocoolers 8. Springer US; 1995. p. 569-79.

256. Corgnale C, Sulic M. Techno-Economic Analysis of High-Pressure Metal Hydride Compression Systems. Metals. 2018 Jun 20;8(6):469.

257. Cox KE, Williamson KD. Hydrogen: Its Technology and Implication: Implication of Hydrogen Energy. Vol. Volume 5-Implication of Hydrogen Energy. CRC Press; 2018.

258. Griffith WA, Flanagan EB. Online, Continuous Monitoring Of Mechanical Condition And Performance For Critical Reciprocating Compressors. Tex AM Univ Turbomach Lab. 2001;

259. Stamatakis E. Benchmark Analysis \& Pre-feasibility study for the market penetration of Metal Hydride Hydrogen Compressor. Integrated, Innovative Renewable Energy - Hydrogen Systems and Applications Workshop. July, 5-7 2017. Athens, Greece.

260. Cornish AJ. Hydrogen Fueling Station Cost Reduction Study. Survey Results and Analysis of the cost and efficiency of various in-operation Hydrogen Fueling Station. Engineering, Procurement \& Construction, LLC. March 2, 2011. Lakewood, Colorado.

261. Lamantia M, Contarini A, Giovanni S. Numerical And Experimental Analysis Of A Linear Compressor. Int Compress Eng Conf Pap 1602 [Internet]. 2002 [cited 2018 Aug 26]; Available from: http://docs.lib.purdue.edu/icec/1602

262. Brunner T. Cryo-compressed Hydrogen Storage. BMW Hydrogen. Hydrogen Storage Workshop. February 15, 2011. Washington DC. 
263. Johnson T. Metal Hydride Compression. Sandia National Laboratories. H2FC Hydrogen and Fuel Cell Program. Project ID PD138. March 28, 2018. [cited 2018 Aug 25]; Available from: https://www.hydrogen.energy.gov/pdfs/review18/pd138_johnson_2018_o.pdf

264. Hyet Hydrogen | Efficient purification \& compression [Internet]. Hyet Hydrogen. 2018 [cited 2018 Aug 28]. Available from: http://hyet.nl/hydrogen/

265. Hamdan M. Electrochemical Compression. 2017 DOE Hydrogen \& Fuel Cells Program. Annual Merit Review Meeting. Giner, Inc.Project ID: PD136. June 6th, 2017. 2017; 